\title{
Alzheimer's Disease is Driven by Intraneuronally Retained Beta-Amyloid Produced in the AD-Specific, BAPP-Independent Pathway: Current Perspective and Experimental Models for Tomorrow
}

\author{
Vladimir Volloch ${ }^{*}$, Bjorn Olsen' and Sophia Rits ${ }^{2,3}$ \\ 'Department of Developmental Biology, Harvard School of Dental Medicine, USA \\ ${ }^{2}$ Division of Molecular Medicine, Children's Hospital, Boston, USA \\ ${ }^{3}$ Department of Biological Chemistry and Molecular Pharmacology, Harvard Medical School, USA
}

\begin{abstract}
A view of the origin and progression of Alzheimer's disease, AD, prevailing until now and formalized as the Amyloid Cascade Hypothesis theory, maintains that the disease is initiated by overproduction of beta-amyloid, $A \beta$, which is generated solely by the $A \beta$ precursor protein, $\beta$ APP, proteolytic pathway and secreted from the cell. Consequent extracellular accumulation of $A \beta$ triggers a cascade of molecular and cellular events leading to neurodegeneration that starts early in life, progresses as one prolonged process, builds up for decades, and culminates in symptomatic manifestations of the disease late in life. In this paradigm, a time window for commencement of therapeutic intervention is small and accessible only early in life. The outlook introduced in the present study is fundamentally different. It posits that the $\beta \mathrm{APP}$ proteolytic/secretory pathway of $\mathrm{A} \beta$ production causes $\mathrm{AD}$ in humans no more than it does in either shortor long-lived non-human mammals that share this pathway with humans, accumulate beta-amyloid as they age, but do not develop the disease. Alzheimer's disease, according to this outlook, is driven by an additional powerful $\mathrm{AD}$-specific pathway of $\mathrm{A} \beta$ production that operates in affected humans, is completely independent of the $\beta$ APP precursor, and is not available in non-human mammals. The role of the $\beta$ APP proteolytic pathway in the disease in humans is activation of the additional $\mathrm{AD}$-specific $\mathrm{A} \beta$ production pathway. This occurs through accumulation of intracellular $\mathrm{A} \beta$, primarily via ApoE-assisted cellular uptake of secreted beta-amyloid, but also through retention of a fraction of $A \beta$ produced in the $\beta$ APP proteolytic pathway. With time, accumulated intracellular $\mathrm{A} \beta$ triggers mitochondrial dysfunction. In turn, cellular stresses associated with mitochondrial dysfunction, including ER stress, activate a second, $\mathrm{AD}$ specific, A $\beta$ production pathway: Asymmetric RNA-dependent $\beta A P P$ mRNA amplification; animal $\beta A P P$ mRNA is ineligible for this process. In this pathway, every conventionally produced $\beta$ APP mRNA molecule serves potentially as a template for production of severely 5 '-truncated mRNA encoding not the $\beta$ APP but its $\mathrm{C} 99$ fragment (hence "asymmetric"), the immediate precursor of A $\beta$. Thus produced, N-terminal signal peptide-lacking C99 is processed not in the secretory pathway on the plasma membrane, but at the intracellular membrane sites, apparently in a neuron-specific manner. The resulting $A \beta$ is, therefore, not secreted but is retained intraneuronally and accumulates rapidly within the cell. Increased levels of intracellular $A \beta$ augment mitochondrial dysfunction, which, in turn, sustains the activity of the $\beta A P P$ mRNA amplification pathway. These self-propagating mutual A $\beta$ overproduction/mitochondrial dysfunction feedback cycles constitute a formidable two-stroke engine, an engine that drives Alzheimer's disease. The present outlook envisions Alzheimer's disorder as a two-stage disease. The first stage is a slow process of intracellular beta-amyloid accumulation. It results neither in significant neurodegenerative damage, nor in manifestation of the disease. The second stage commences with the activation of the $\beta A P P$ mRNA amplification pathway shortly before symptomatic onset of the disease, sharply increases the rate of $\mathrm{A} \beta$ generation and the extent of its intraneuronal accumulation, produces significant damages, triggers $\mathrm{AD}$ symptoms, and is fast. In this paradigm, the time window of therapeutic intervention is wide open, and preventive treatment can be initiated any time, even late in life, prior to commencement of the second stage of the disease. Moreover, there are good reasons to believe that with a drug blocking the $\beta A P P$ mRNA amplification pathway, it would be possible not only to preempt the disease but also to stop and to reverse it even when early AD symptoms have already manifested. There are numerous experimental models of $\mathrm{AD}$, all based on a notion of the exceptionality of $\beta \mathrm{APP}$ proteolytic/secretory pathway in $\mathrm{A} \beta$ production in the disease. However, with no drug even remotely effective in Alzheimer's disease, a long list of candidate drugs that succeeded remarkably in animal models, yet failed utterly in human clinical trials of potential AD drugs, attests to the inadequacy of currently employed AD models. The concept of a renewable supply
\end{abstract}

Citation: Volloch V, Olsen B, Rits S. Alzheimer's Disease is Driven by Intraneuronally Retained Beta-Amyloid Produced in the AD-Specific, BAPP-Independent Pathway: Current Perspective and Experimental Models for Tomorrow. Ann Integr Mol Med. 2020; 2(1): 1007.

Copyright: @ 2020 Vladimir Volloch

Publisher Name: Medtext Publications LLC

Manuscript compiled: April $08^{\text {th }}, 2020$

*Corresponding author: Vladimir Volloch, Department of Developmental Biology, Harvard School of Dental Medicine, USA, E-mail: vladimir.volloch@gmail.com; vladimir_volloch@hms.harvard.edu of beta-amyloid, produced in the $\beta$ APP mRNA amplification pathway and retained intraneuronally in Alzheimer's disease, explains spectacular failures of both BACE inhibition and A $\beta$-immunotherapy in human clinical trials. This concept also forms the basis of a new generation of animal and cellbased experimental models of $\mathrm{AD}$, described in the present study. These models incorporate $\mathrm{A} \beta$ - or C99-encoding mRNA amplification pathways of $A \beta$ production, as well as intracellular retention of their product, and can support not only further investigation of molecular mechanisms of AD but also screening for and testing of candidate drugs aimed at therapeutic targets suggested by the present study.

Keywords: Alzheimer's disease; $\beta$ APP-independent generation of betaamyloid; Asymmetric RNA-dependent beta-APP mRNA amplification; Intracellular retention of $\mathrm{A} \beta$; Mitochondrial dysfunction-related stresses 


\section{Introduction}

Alzheimer's disease (AD) is a devastating neurodegenerative disorder that develops late in life in case of sporadic disease (SAD) or at midlife in familial AD cases (FAD). Although many factors contribute to $\mathrm{AD}$ pathogenesis, it is strongly believed that the disease is initiated and driven by the overproduction and accumulation of beta-amyloid $(A \beta)$, a peptide derived by proteolytic cleavages of a large betaamyloid precursor protein ( $\beta \mathrm{APP})$. This notion was formalized in the Amyloid Cascade Hypothesis (ACH), which became a prevailing evidence-based theory of $\mathrm{AD}$, and $\mathrm{A} \beta$ emerged as the most extensively researched, validated, and compelling therapeutic target of the disease. During the last two decades, a large number of candidate drugs has been generated, tested, and progressed to human clinical trials. They include inhibitors of beta-amyloid aggregation (scillo-inositol, PBT2, tramiprosate), $\mathrm{A} \beta$ antigens (vanutide, AD02, CAD-106, AN-1792), monoclonal antibodies targeting $A \beta$ (crenezumab, gantenerumab, solanezumab, bapineuzumab, ponezumab), immunoglobulins (polyclonal antibodies) targeting $\mathrm{A} \beta$, gamma-secretase (gammasite $\beta$ APP cleaving enzyme) inhibitors (avagacestat, begacestat, semagacestat), gammasecretase modulators such as tarenflurbil, beta-secretase (beta-site amyloid precursor protein cleaving enzyme, BACE) inhibitors (atabecestat, lanabecestat, AZD3839, LY2811376, LY2886721, verubecestat). However, all candidate drugs tested failed in advanced human clinical trials involving either mild-to-moderate $\mathrm{AD}$ patients or persons with mild cognitive impairment and biomarker evidence of $\mathrm{A} \beta$ deposition in brain (prodromal AD). Moreover, in a number of trials the administration of drugs actually worsened the cognitive or clinical condition of the subjects.

Remarkably, all these potential drugs progressed to human Alzheimer's disease clinical trials because they were highly effective and elicited strong positive responses in preclinical studies, in healthy human volunteers, and in animal models of AD. Indeed, they were shown to antagonize beta-amyloid aggregation, decrease its production, and increase its clearance. In animal models of the disease, some of the drugs were shown to repair symptomatic defects and even to reverse neurodegeneration. Why such a discordance between the outcomes seen in animal models and those obtained in human clinical trials? To attain better perspective of cellular events involved in the origination and development of $\mathrm{AD}$, it is instructive to address the apparent exclusivity of the disease to Homo sapiens. Two features are of key importance in comparisons of humans versus non-human mammals. First, all non-human mammals tested to date accumulate $A \beta$ as they age but do not develop $A D$. This is true for smallsized, short-lived animals such as mice, and for large-sized, long-lived non-human mammals such as elephants. In contrast, humans do both. It appears, therefore, that the extent of increase in beta-amyloid levels, sufficient to trigger amyloid cascade culminating in $\mathrm{AD}$, can be reached physiologically in humans but not in non-human mammals. This disparity could be easily explained if different pathways of betaamyloid generation were employed in these instances. This is not the case, however: The same $A \beta$ production pathway, proteolysis of betaamyloid precursor protein, is utilized in non-human mammals and in healthy humans, as well as in $\mathrm{AD}$ patients. A second feature of key importance is that when the disease is forced, at least symptomatically, upon non-human mammals by genetic manipulations that drastically increase beta-amyloid production by the normally employed $\beta$ APP proteolytic pathway, treatment with agents blocking the $A \beta-$ generating proteolytic pathway mitigate and even reverse both neurodegeneration and the $\mathrm{AD}$ symptoms. Conversely, the same treatments are completely ineffective in human Alzheimer's patients.
Taken together, the above considerations leave us with an alternative explanation: In $\mathrm{AD}$, in addition to a beta-amyloid production pathway common to non-human mammals and healthy humans, another, qualitatively different pathway of $A \beta$ generation, exclusive to Alzheimer's disease, is in operation, and it is this pathway that drives the disease. It appears that the approaches used in generating animal models, namely, "humanizing" murine $\mathrm{A} \beta$ (three amino acid residues of mouse $A \beta$ differ from those of its human counterpart), utilizing modified human $\beta$ APP transgene or its portions, introducing FADassociated mutations of $\beta$ APP, expressing factors known to facilitate the disease, such as specific alleles of ApoE, defined mutations of presenilins, and certain types of micro RNA, all based on a notion of the exceptionality of the $\beta A P P$ proteolytic/secretory pathway in $A \beta$ production in Alzheimer's disease, are insufficient for producing an adequate model of Alzheimer's disease, because all of the above techniques, either individually or in combinations, do not recapitulate the disease mechanistically. It seems, therefore, that a new generation of conceptually different $A D$ models is needed, both for screening of candidate drugs and for basic research. These conclusions are best illustrated by an example of the development, evaluation and trials of BACE inhibitors.

Results obtained with BACE Inhibitors Indicate that in Alzheimer's Disease, $A \beta$ is Produced by an AD-Specific Pathway, Absent in Non-Human Mammals and in Healthy Humans, and Independent of $\beta$ APP

\section{Pathway of beta-amyloid generation common to humans and non-human mammals}

Beta-amyloid, the peptide associated with and widely believed to have a pivotal early role in etiology of Alzheimer's disease, was shown to be generated, both in humans and in non-human mammals, by proteolytic cleavages of a much larger molecule, betaamyloid precursor protein, $\beta$ APP. This precursor can be cleaved by three enzymes designated alpha- beta- and gamma-secretases, each at a specific position. The cleavages can proceed in two separate pathways, with only one generating $A \beta$. In the non-amyloidogenic proteolytic pathway, a cleavage by the alpha-secretase occurs within the $A \beta$-containing segment of $\beta$ APP, thus preventing the generation of beta-amyloid. In the amyloidogenic proteolytic pathway, two sequential cleavages of $\beta$ APP are involved in the production of $A \beta$. The first is a cleavage of $\beta$ APP by the beta-secretase. It occurs between residues 671 and 672 of the $\beta A P P$ molecule (isoform 770 numbering), generating the $\mathrm{N}$-terminus of $\mathrm{A} \beta$, yielding the $12 \mathrm{kDa}$ membrane-bound C-terminal fragment, C99 (residues 672-770), releasing a large ectodomain of $\beta$ APP, soluble sAPP $\beta$ (residues 1-671), and precluding activity of alpha-secretase which cleaves $\beta$ APP within its $A \beta$-containing segment but cannot cut within C99 or $A \beta$ [1-3]. The second cleavage, by gamma-secretase activity, occurs at one of closely clustered multiple sites within the C99 fragment, around 40 amino acid residues downstream from its $\mathrm{N}$-terminus and generates the $C$-terminus of $A \beta$. Thus released, $A \beta$ is secreted from the cell. The size of $A \beta$ ranges from 36 to 43 amino acid residues, with $A \beta 40$ being the most abundant species normally formed. Studies of the inherited forms of the disease, FAD, strongly indicated that cerebral $A \beta$ accumulation is essential for and underlies the etiology of the disease [4-6]. This notion provides the basis for the Amyloid Cascade Hypothesis [7-12], which has become the dominant model of $\mathrm{AD}$ pathogenesis and has guided the development of potential treatments. Most therapeutic strategies attempted to date have been based 
on this model, and virtually all preclinical tests and clinical trials discussed below have been designed within the framework of the $\mathrm{ACH}$. Over two hundred autosomal dominant mutations associated with FAD have been identified in genes for $\beta A P P$ and presenilins, the components of the gamma-secretase complex [6]. In the $\beta$ APP gene, most of the mutations cluster around alpha-, beta-, and gammasecretase cleavage sites and increase either the production of total $A \beta$ or the relative proportion of a more neurotoxic 42-residue form of $A \beta, A \beta 42$. In terms of the $A C H$, there is little doubt that abnormal processing of $\beta \mathrm{APP}$ and increased production of total $A \beta$ or its 42 -amino acid residues isoform are pivotal events in the pathogenesis of FAD. Although the number of individuals affected by FAD is substantial, this form of the disease is quite rare in relative terms, representing less than $5 \%$, in fact less than $1 \%$ by some estimates, of the total Alzheimer's disease burden [5,13-15]. Since the pathological lesions and symptoms in the non-hereditary form of the disease, SAD, are analogous to those seen in the familial forms, it has been assumed that abnormal amyloidogenic proteolytic processing of $\beta$ APP of a type seen in FAD also underlies the pathogenesis of SAD [4,5]. The assumption that the $\mathrm{ACH}$ applies to both forms of $\mathrm{AD}$ implies that any therapeutic approach effective in FAD would also be successful in treatment of SAD.

\section{Success of beta-secretase inhibitors in preclinical tests}

The elucidation of the $\beta$ APP proteolytic pathway resulting in generation of $A \beta$ suggested rational design of a treatment for Alzheimer's disease. Indeed, in light of the above discussion, betasecretase activity was viewed as a strategic target of choice: Inhibit beta-secretase cleavage and there is no beta-amyloid. Moreover, such inhibition would shift the equilibrium between alpha- and betasecretase cleavages toward the former, thus augmenting its efficacy. Therefore, since the identification of beta-site APP-cleaving enzyme (BACE) as beta-secretase [16-18], it became the primary therapeutic target for treatment of AD. Designing BACE-inhibiting agents presented major challenges of cell penetration, oral bioavailability, metabolic clearance, and brain access, but intense efforts, mainly by the pharmaceutical industry, led to development of a number of brainpenetrant small-molecule BACE inhibitors that have been vigorously investigated. The results obtained in the early investigations of BACE inhibition, first appearing around 2007 [19-27], are truly striking. As an example, Merck researchers reported in 2012 the discovery of "compound 16", which robustly reduced cortex and CSF levels of $\mathrm{A} \beta$ when administered orally to rats [28]. Continuous efforts to improve upon "compound 16" culminated in the development of verubecestat (MK-8931). Preclinical tests of this agent achieved dramatic results [29]. Levels of $A \beta$ and sAPP $\beta$ were reduced by up to $90 \%$ in plasma, brain, and CSF after even a single administration of verubecestat to healthy subjects including rats, monkeys, and human volunteers [29]. The acute reduction of over $80 \%$ in CSF and cortical $\mathrm{A} \beta$ and sAPP $\beta$ produced by verubecestat was maintained after chronic administration for nine months in monkeys [29]. Because of its favorable initial safety profile and its ability to markedly reduce cerebral and CSF A $\beta$ and $\operatorname{SAPP} \beta$ concentrations, verubecestat was the first BACE inhibitor to progress to phase III clinical trials. Preclinical evaluation of a number of independently developed BACE inhibitors, such as BI1181181, LY2811376, LY2886721, AZD3293 (lanabacestat, LY3314814), CNP520, E2609 (elenbacestat), JNJ-54861911, CTS21166, HPP854, PF-05297909, RG7129, TAK-070, VTP-37948 yielded similarly impressive results in animals and healthy volunteers and all these agents have entered clinical trials.

\section{BACE inhibition rescues functional impairments in animal models of Alzheimer's disease}

With the ability to significantly reduce the production and lower the levels of $A \beta$ thus established, the question remained whether such a reduction would translate into a "treatment" of the disease. This question was answered resolutely and convincingly, with animal models bioengineered to mimic FAD and overproducing $A \beta$ solely by the $\beta$ APP proteolytic pathway, in two recent studies using different approaches to inhibit the beta-secretase activity. One study utilized BACE inhibitor NB-360 [30]. It was based on a previous study [31] showing NB-360 to be a potent, brain penetrable BACE inhibitor capable of completely blocking $A \beta$ deposition in the brains of $\beta$ APP transgenic mice, as well as of rats and dogs. Moreover, this inhibitor blocked accumulation of activated inflammatory cells in the brains of $\beta$ APP transgenic mice. The more recent study with NB-360 [30] further assessed the notion that suppression of $A \beta$ production can have beneficial downstream effects on the progression of Alzheimer's disease. Using histochemistry, in vivo imaging, and behavioral analyses in a mouse model of $\mathrm{AD}$, the authors demonstrated that along with reducing prefibrillary $A \beta$ surrounding plaques, the inhibition of BACE activity rescued neuronal hyperactivity, impaired long-range circuit function and memory defects. That all these effects were due to inhibition of $A \beta$ production was strongly indicated by the observation that functional neuronal impairments reappeared after infusions of soluble $\mathrm{A} \beta[30]$.

In the second study [32], mimicking BACE1 inhibition in adult organisms, the authors generated BACE1 conditional knockout $\left(\mathrm{BACE}^{\mathrm{f} / \mathrm{f} / \mathrm{I}}\right)$ mice and bred them with ubiquitin-Cre mice to induce deletion of BACE1 after passing early developmental stages. Strikingly, sequential deletions of BACE1 in an adult AD mouse model were capable of reversing amyloid deposition and resulted in significant improvement in gliosis and neuritic dystrophy. Moreover, in correlation with amyloid plaque reversal, it also significantly improved synaptic functions, as was determined by long-term potentiation and contextual fear conditioning experiments. These studies offered great hope that sustained inhibition of BACE activity can constitute a treatment, or at least be beneficial, for AD patients. This assumption was tested in several advanced human clinical trials.

\section{BACE inhibition is completely ineffective in Alzheimer's disease}

The results of clinical trials of BACE inhibitors in humans, however, do not support this assumption. All BACE inhibitor clinical trials that ended to date, ended in failure. Some trials, such as that of BI1181181, LY2811376, LY2886721 and RG7129, were terminated because of technical and safety issues. On the other hand, there were no such issues in the trials of the verubecestat (MK-8931). This agent was shown to be very efficient in suppressing $A \beta$ production in preclinical tests and was proven safe in clinical trials. Yet, its Phase III, 2000 patient-strong "EPOCH" trial in mild to moderate AD patients was terminated prematurely for the lack of efficacy, with an interim analysis by an external data-monitoring committee giving the trial "virtually no chance of finding a positive effect". Similarly, a separate large Phase III clinical trial of verubecestat in prodromal AD patients, the "APECS", was also terminated prematurely and for the same reason, lack of efficacy. The clinical trials of several other BACE inhibitors are still in progress but the verubecestat results do not inspire confidence in their successful outcomes. 


\section{Results of clinical trials in humans can be explained by $\beta A P P$-independent and therefore BACE inhibition- insensitive generation of beta-amyloid in Alzheimer's disease}

One rational explanation for the strikingly different effects of BACE inhibition in animal models and healthy human subjects and in Alzheimer's disease is that in $\mathrm{AD}$, in addition to the conventional $\beta A P P /$ beta-secretase-dependent component of $A \beta$ production that operates in non-human mammals, healthy humans and $\mathrm{AD}$ models described above, there is another, unconventional, $A \beta$-generating component in operation, possibly facilitated or enabled by epigenetic changes associated with the disease [33], which is $\beta A P P-i n d e p e n d e n t$ and bypasses the requirement for beta-secretase activity. In these $\mathrm{AD}$ cases, administration of effective BACE inhibitors would suppress the $\beta A P P-d e p e n d e n t$ component, but would have no effects on the second, $\beta A P P-$ and beta-secretase-independent, component. The extent of suppression of total $\mathrm{A} \beta$ production by $\mathrm{BACE}$ inhibitors would depend on the relative input of two components in the generation of $A \beta$; if the input of the second significantly exceeds that of the first component, BACE inhibitors would be ineffective both in lowering $A \beta$ levels and in the treating the Alzheimer's disease.

Beta-Amyloid Produced in AD-Specific, BAPP-Independent Pathway is Retained Intracellularly

Taken together, the results of BACE inhibition studies and trials described above can be summarized in the following:

(a) Only one $A \beta$ production pathway, that of $\beta A P P$ proteolysis by beta-and gamma-secretases, is operating in non-human mammals and in healthy humans;

(b) In addition to $\beta A P P$ proteolytic pathway common to animals and healthy humans, another, AD-specific, pathway is in operation in Alzheimer's disease;

(c) The additional $A \beta$ production pathway operating in $A D$ is qualitatively different in that it is $\beta A P P$-independent;

(d) This additional pathway is also quantitatively different in that it is the predominant process of beta-amyloid production in Alzheimer's disease;

(e) Importantly, beta-amyloid produced in the AD-specific pathway is retained intraneuronally.

The conclusions (a) trough (d) follow from the results described above. The conclusion (e) is based on the observation that in verubecestat stage III human clinical trials, a strong dose-related suppression of levels of $\mathrm{A} \beta$ and $\mathrm{sAPP} \beta$, both products of BACE cleavage of the amyloid precursor protein, was seen in patients' cerebrospinal fluid [34]. In the high dosage $(40 \mathrm{mg})$ group, levels of $A \beta 40, A \beta 42$, and $s A P P b$, all decreased by over $80 \%$, indicating that the drug reached the brain, turned off production of $A \beta$ by the $\beta$ APP proteolytic pathway, and suppressed levels of extracellular beta-amyloid. To reconcile this observation with findings (b), (c) and (d) above, we come to the inescapable conclusion that beta-amyloid produced by the predominant AD-specific pathway is not secreted but is retained within the cell and, consequently, that Alzheimer's disease is driven by this intraneuronally retained $A \beta$. It should be mentioned that the above notion of intracellularly retained $A \beta$ as a driver of $\mathrm{AD}$ also explains highly contrasting results obtained with $\mathrm{A} \beta$ immunotherapy, namely a remarkable therapeutic efficiency in animal models of AD lacking large intracellular $\mathrm{A} \beta$ pools [35], and marked inefficacy in $\mathrm{AD}$ clinical trials in humans [36], where putative large renewable pools of intracellularly retained beta-amyloid produced in the postulated $\mathrm{AD}$-specific pathway are inaccessible to $\mathrm{A} \beta$-targeting antibodies.

Whereas the postulated scale of intraneuronal production/ retention of beta-amyloid is unparalleled in that it applies to the entire output of the predominant $A \beta$ production pathway, a notion of intracellular $A \beta$, albeit as a fraction of its secreted counterpart, is not unprecedented. Intracellular $A \beta$ was indeed observed in the brain. In $\mathrm{AD}$, it is frequently associated with neurofibrillary tangles (NFTs)-containing neurons [37-39]. In patients with mild cognitive impairment, intraneuronal $A \beta$ was reported in hippocampus and ectorhinal cortex [38] regions more prone to $\mathrm{AD}$ pathology, suggesting that the accumulation of intraneuronal $A \beta$ is an early event in the progression of $\mathrm{AD}$. As $\mathrm{AD}$ progresses, neuronal lysis and release of intraneuronal beta-amyloid contributes to the extracellular pool of $A \beta$ [36]. It appears that most of the intraneuronal $A \beta$ is the more toxic $A \beta 42$ rather than $A \beta 40$ [36]. There are two potential sources of intracellular $A \beta$. The more studied and understood source is cellular uptake of secreted extracellular beta-amyloid. Data obtained conclusively show that soluble $A \beta 42$ and $A \beta 40$ use endocytosis [40] to enter the cell and that $A \beta 42$ is taken up two times more efficiently than $A \beta 40$ [61]. Beta-sheet-rich $A \beta 42$ aggregates were observed to enter cells at low nanomolar concentrations [41]. In contrast, monomers were shown to bound to plasma membrane and to form aggregates there before cellular uptake and accumulation in endocytic vesicles [42], thus indicating that formation of $A \beta$ aggregates may be a prerequisite for cellular uptake [40-43]. Moreover, it was suggested that oligomer-specific $A \beta$ toxicity in cell models is mediated by its selective uptake [40]. Cellular uptake of $A \beta$ was also shown to be ApoE isoform-dependent and mediated by lipoprotein receptor LR11/ SorLA [42]. ApoE4, a major genetic risk factor for AD, was much more efficient in mediating $A \beta$ uptake than ApoE3 and ApoE2 [42]. LRP, another member of the lipoprotein receptor family, binds to $A \beta$ directly or through ligands such as ApoE and undergoes endocytosis, thus facilitating cellular uptake of $A \beta$ [44]. The internalization of extracellular $A \beta$ can also be mediated by $\alpha 7$ nicotinic acetylcholine receptor [45-47], the scavenger receptor for advanced glycation, RAGE [48-50], the formyl peptide receptor-like 1, FPRL1 [51], and $\mathrm{N}$-methyl-d-asparate, NMDA, receptors [52]. A $\beta$ internalization was observed in multiple cell types, including neurons, astrocytes, glial cells and macrophages where it appears to play different roles, and it occurs in cells of normal subjects as well as in cells of $\mathrm{AD}$-affected individuals [36].

The other potential source of intracellular $A \beta$ is its retention within the cell. Whether $A \beta$ is retained intracellularly or is secreted into the extracellular pool is defined by the location at which the immediate beta-amyloid precursor, the $\mathrm{C} 99$ fragment, is cleaved by the gammasecretase complex. The vast majority of $\mathrm{A} \beta$ produced in the $\beta \mathrm{APP}$ proteolytic pathway is generated by cleavage at the plasma membrane and is secreted. However, cleavage can also occur in the endoplasmic reticulum (ER) [53], Golgi and trans Golgi network (TGN) [54], and at endosomal [53], lysosomal [53] and mitochondrial [55] membranes; such cleavages generate intracellularly retained $A \beta$. It has been shown that different isoforms of intracellular $A \beta$ can be generated at different locations. For example, cleavage within the ER produces predominantly A $\beta 42$ [56-60] whereas cleavage within the TGN mostly generates $A \beta 40$ [67]. Interestingly, these locations of intracellular $A \beta$ generation 
are limited to neurons [60]. Recent evidence suggests that subcellular localization of presenilin2 (PSEN2) directs the assembly of gammasecretase complex to specific cellular compartments and thus contributes to the balance between intracellular accumulation and secretion of $A \beta$ [61,62]. Moreover, FAD-associated PSENs mutations were shown to pronouncedly augment the intracellular pool of $A \beta$ by determining localization and substrate specificity of gamma-secretase [62].

Intracellular accumulation of $A \beta$ was shown to have pathological consequences; for example, inhibition of the ubiquitin-proteosome system and potential facilitation of the build-up of tau protein [6366]. Importantly for the discussion below, accumulation of $A \beta$ has been observed in mitochondria [67]. In these organelles, all subunits of the gamma-secretase complex were shown to be present, suggesting that beta-amyloid could be generated locally, within the mitochondria, by gamma-cleavage of $A \beta$ precursor, in addition to the cellular uptake of $A \beta$ and its production at other intracellular sites followed by trafficking to mitochondria [68]. Progressive age-related accumulation of intracellular $A \beta$ in mitochondria has been associated, along with a number of other mitochondrial defects, with diminished enzymatic activity of respiratory chain complexes and a reduced rate of oxygen consumption [69]. Multiple defects, many believed to be caused by $\mathrm{A} \beta$, result in mitochondrial dysfunction, a potential trigger of the $\mathrm{AD}$-specific, $\beta \mathrm{APP}$-independent $\mathrm{A} \beta$ generation pathway (discussed below). Importantly, mitochondrial $A \beta$ has been identified as a focal point for neuronal metabolic dysfunction in Alzheimer's disease [69].

Neither cellular uptake of $A \beta$ nor its intraneuronal generation/ retention by the $\beta$ APP proteolytic pathway, however, could be the major source of a large $\mathrm{AD}$-specific pool of intraneuronal beta-amyloid postulated above. Indeed, if the $\beta$ APP proteolytic pathway were the only source of the intraneuronal $A \beta$, either through secretion/uptake or through intracellular generation/retention, or both, its suppression by BACE inhibitors in human $\mathrm{AD}$ trials would result in clearance of the intracellular $A \beta$ pool, by cutting supply through clearance of extracellular soluble $A \beta$, the source of uptake, and turning off $\beta$ APP proteolysis, the source of intracellular $A \beta$ generation, and in beneficial outcomes that were not seen. This reasoning is consistent with and supportive of the conclusions formulated at the beginning of this section. It further accentuates the notion of an $\mathrm{AD}$-specific pathway of $A \beta$ production operating exclusively in Alzheimer's disease. What could this pathway be?

\section{Alzheimer's Disease-Specific, BAPP- Independent $\mathbf{A} \beta$ Production Pathway: RNA- Dependent Amplification of Human BAPP mRNA}

In considering a mechanism underlying the postulated additional pathway of $A \beta$ production in Alzheimer's disease, one requirement clearly stands out. Since it is presumably $\beta$ APP- and beta-secretaseindependent, the $\mathrm{N}$-terminus of the resulting polypeptide generated by such a mechanism should be precisely that of $A \beta$ (it can be longer than $A \beta$ at its $C$-end and be trimmed to size by gamma-secretase cleavage). This is an exceedingly tall order, yet, as described below, it can be accomplished by a process known as "chimeric RNAdependent mammalian mRNA amplification" [70-75].

\section{“Chimeric" pathway of mammalian RNA-dependent mRNA amplification}

De novo production of RNA on an RNA template, a process known as RNA-dependent RNA synthesis (RdRs), and the enzymatic activity conducting it, RNA-dependent RNA polymerase (RdRp), were initially considered to be exclusively virus-specific. Eventually, however, the occurrence of RdRs and the ubiquitous presence of conventional $\mathrm{RdRp}$ were demonstrated in numerous eukaryotic organisms [76]. The evidence that the enzymatic machinery capable of RdRs is present in mammalian cells was derived from studies of RNA viruses, such as hepatitis delta virus, HDV, that do not encode RdRp, yet undergo a robust RNA replication once inside the mammalian host [76-78], thus firmly establishing its occurrence and functionality. Moreover, it became clear that RdRp activity, apparently in a non-conventional form [79-81], is constitutively present in most, if not all, mammalian cells. Because such activity was shown to produce short transcripts, because of its apparent involvement in RNA interference phenomena, and because double-stranded RNA is known to trigger cellular responses leading to its degradation, it was generally assumed that its role in mammalian cells is restricted to a regulatory function. However, at the same time, an enzymatic activity, capable of generating complete antisense RNA complements of mRNAs, was discovered in mammalian cells undergoing terminal differentiation [82]. Moreover, observations of widespread synthesis of antisense RNA initiating at the 3'poly(A) of mRNAs in human cells [83] suggested an extensive cellular utilization of mammalian RdRp activity. These results led to the development of a model of RdRpfacilitated and antisense RNA-mediated amplification of mammalian mRNA [84-86]. Recent detection of the major model-predicted identifiers, chimeric RNA intermediates containing both sense and antisense RNA strands covalently joined in a rigorously predicted and uniquely defined manner [86,87], as well as the identification of a putative chimeric RNA end product of this process [86], validated the proposed model.

The process of RNA-dependent amplification of mammalian mRNA is described in detail elsewhere $[85,86]$. Here, it is diagrammed in Figure 1 and can be briefly summarized as follows. The amplification process occurs in the cytoplasm and starts with transcription of the antisense complement from a conventional, spliced mRNA template, initiating at the 3'poly(A), possibly with the help of a uridilated protein, as seen in viral RdRs [88] (Figure 1, Step 1), and terminating at the 3'end with the "C", a transcript of the capG of mRNA [85-87]. Generation of a complete antisense transcript requires the presence of an eligible RNA template and a compatible polymerase activity. The only major prerequisite for a potential RNA template appears to be the presence of the poly(A) segment at its 3 ' terminus [83-86]. The compatible polymerase activity is RdRp. The RdRp activity in mammalian cells appears to be nonconventional; two possible candidates for this role are the RNA polymerase II complex or its components $[79,80]$ and RdRp activity of the TERT complex [81], both ubiquitously present in all cells.

Under regular circumstances, the RdRp activity in mammalian cells produces only short antisense RNA transcripts. For example, a widespread synthesis of diverse short antisense RNA transcripts initiating at the 3'poly(A) of mRNA was observed in human cells [83]. On the other hand, RdRp activity isolated from rabbit reticulocytes [82] was able to produce, in assays, long antisense RNA transcripts. Subsequent studies identified full-length antisense transcripts of globin mRNA in erythroid cells [84-86]. It could be argued that the component responsible for the production of long antisense transcripts in mammalian cells is a processivity conferring co-factor of RdRp activity that is induced under special circumstances when overproduction of specific proteins is required [85-87]. The notion of a processivity co-factor is strongly supported by studies of HDV 
replication in "normal" (i.e. apparently lacking processivity cofactor) mammalian cells [76-78]. Within the framework of the above considerations, the ability of RdRp-deficient viruses to use RdRp activity of mammalian cells for their replication implies that they should encode a processivity co-factor of cellular RdRp. In case of HDV, it appears to be hepatitis delta antigen HDAg, the only protein encoded by HDV. HDAg is essential both for production of long transcripts by cellular RdRp, and for viral replication [78]. In its absence only short transcripts are generated [78]. These observations provide a proof of concept for the notion of RdRp processivity co-factor, central for our understanding of mammalian mRNA amplification. Identification of a cellular homolog of HDAg, DIPA [89,90], suggests directions for a search for the cellular RdRp processivity co-factor.
The resulting double stranded sense/antisense structure is then separated into single-stranded molecules by a helicase activity that mounts the poly(A) segment of the 3'poly(A)-containing strand (the sense-oriented strand) of the double helical structure and proceeds along this strand modifying, on average, every fifth nucleotide in the process $[85,86]$ (Figure 1, Step 2). Only purines, the "A" and the "G" appear to be modified in the separation/modification process $[85,86]$. The 5' poly(U)-containing antisense strand remains unmodified during and after the separation [84-86]; this being essential, as described below, for the production of a new sense strand since modifications were shown to interfere with and would preclude complementary interactions required in this process $[85,86]$.

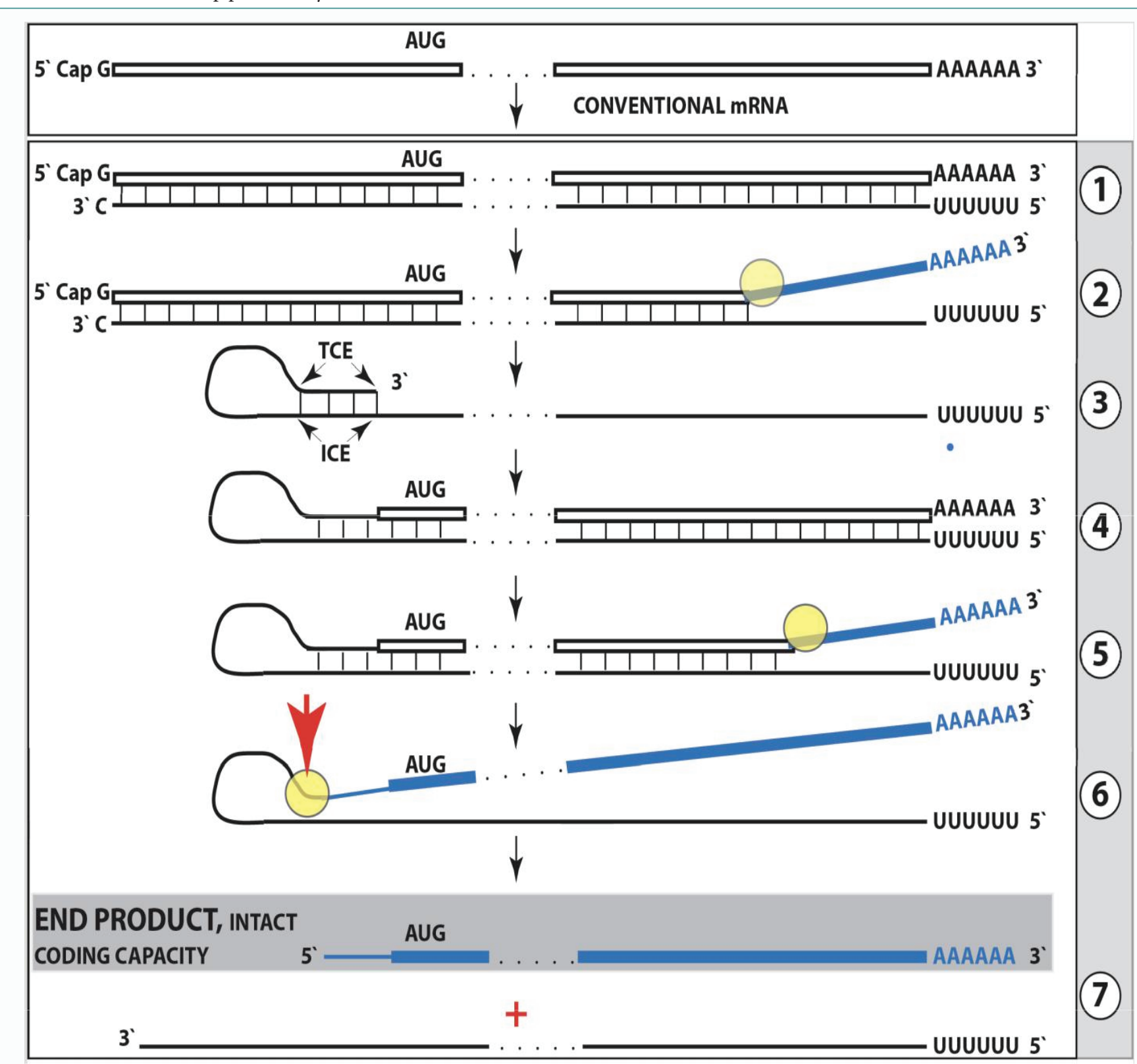

Figure 1: Projected stages of the chimeric pathway of RdRp-facilitated, antisense RNA-mediated amplification of mammalian mRNA. Top panel: Conventional, genome-originated mRNA molecule. Bottom panel: Projected stages of antisense RNA-mediated mRNA amplification. Boxed line - sense strand RNA. Single line - antisense strand RNA. "AUG" - functional translation initiation codon (could be other than "AUG"). "TCE"- 3'-terminal complementary element; "ICE"- internal complementary element, both on the antisense RNA strand. Yellow circle - helicase/modifying activity complex. Blue lines (both single and boxed) - RNA strand modified and separated from its complement by a helicase complex. Red arrowhead - position of cleavage of the chimeric intermediate. Step 1: Synthesis of antisense strand; step 2: Strand separation; step 3: Folding of antisense strand into self-priming configuration; step 4: Extension of self-primed antisense RNA; step 5: Strand separation; step 6: Cleavage of the chimeric intermediate; step 7: End-products of amplification. Note that chimeric RNA end product retains the intact coding capacity of conventional mRNA. 
The vast majority of mammalian mRNA species contains 3'-terminal poly(A) segments. The notion that many, or possibly most, of them could be eligible templates for RdRp was suggested in our previous studies [84-86]. Subsequent observations by Kapranov et al. showed a widespread synthesis of antisense RNA initiating, apparently indiscriminately, at the $3^{\prime}$ poly(A) of mRNA in human cells [83]. This, seemingly undiscerning, RdRp template eligibility of the bulk of mammalian mRNA species raises questions with regard to mechanisms underlying the manifestly stringent specificity of the mRNA amplification process [84-86]. The specificity of mRNA amplification appears to be determined at the 3' terminus of an antisense transcript by its ability or inability to support production of a complementary sense strand RNA molecule, the end product of the amplification process.

The generation of a sense strand on an antisense template occurs via the extension of the 3' terminus of a self-primed antisense template and requires the presence within the antisense transcript of two spatially independent complementary elements $[85,86,91]$. One of these is the strictly $3^{\prime}$-Terminal Complementary Element (TCE), the other is the Internal Complementary Element (ICE). These elements (Figure 1, Step 3) must be complementary to a sufficient extent to form a priming structure but may contain mismatches and utilize unconventional G/U pairings [85-87]. In addition, the selfpriming structure must accommodate the additional 3'-terminal "C", a transcript of the 5'cap"G" of mRNA[86,87]. The generation of a sense strand also requires the thermodynamic feasibility, enhanced/ enabled by the occurrence of two complementary and topologically compatible elements, of the antisense strand folding into a selfpriming configuration.

Provided that a self-priming structure is formed, the 3 ' end of the folded antisense strand is extended by RdRp into a sense-orientation molecule terminating with the poly(A) at the 3 'end (Figure 1, Step 4), thus generating a hairpin-structured chimeric intermediate consisting of covalently joined sense and antisense strands. The double stranded portion of the resulting structure is separated by a helicase activity invoked above, which mounts the 3'poly(A) of a newly synthesized sense strand component of the chimeric intermediate and proceeds along this strand in the 5 ' direction modifying the molecule as it advances (Figure 1, Step 5). When the helicase activity reaches a single stranded portion of the hairpin structure, it, or associated activities, cleave the molecule either within the TCE, at a TCE/ICE mismatch, or immediately upstream of the TCE (red arrowhead, Figure 1, Step 6); the cleavage occurs between the 5 ' hydroxyl group and the 3 ' phosphate $[85,86]$.

Strand separation, in conjunction with the cleavage, produces two single-stranded molecules (Figure 1, Step 7) one of which is a chimeric mRNA, the functional mRNA end product of amplification and the basis for defining this pathway as the "chimeric". The chimeric nature of this end product is due to the presence at its 5' end of a 3'-terminal segment of the antisense strand consisting, depending on the site of cleavage of the chimeric intermediate, of either the entire TCE or a portion thereof covalently attached, in a 5' to 3 ' orientation, to the $5^{\prime}$-truncated sense strand. This chimeric molecule is modified and 3 ' polyadenylated. In contrast to conventional mRNA that can be repeatedly used as $\operatorname{RdRp}$ template $[85,86]$, it cannot be further amplified because its antisense complement would be lacking the TCE, but can be translated into the conventional mRNA-encoded polypeptide $[85,86]$. In the chimeric pathway of mRNA amplification, the cleavage of the chimeric intermediate, following the strand separation and the associated modification of the poly(A)-containing strand of the double-stranded hairpin structure, is the ultimate act in the generation of the chimeric mRNA end product. Consequently, it is formed already modified and is never present in the unmodified form [85-87]. Therefore, because the modified amplified RNA is resistant to reverse transcription $[85,86]$, it cannot be detected by conventional reverse transcription-based sequencing methods.

The chimeric RNA-dependent mRNA amplification process illustrated in Figure 1 above results in an mRNA molecule containing the entire protein-coding region of a conventional, genome-transcribed, mRNA and can be translated into the original, conventional mRNAencoded, polypeptide $[85,86]$. If this process were to apply to $\beta A P P$ mRNA, it would result in the complete $\beta$ APP polypeptide. However, in the proposed scenario of $\beta$ APP-independent generation of betaamyloid in Azheimer's disease, the expected translational outcome is only the C-terminal fragment, CTF, of the beta-amyloid precursor protein. Such an outcome can indeed be achieved in an asymmetric RNA-dependent mRNA amplification pathway.

\section{Asymmetric RNA-dependent mRNA amplification pathway}

In the scenario discussed in the preceding subsection, both complementary elements required for an appropriate folding and self-priming of the antisense strand, TCE and ICE, are located within its segment corresponding to the 5'UTR of a conventional genomeencoded mRNA. In such a situation, depicted in steps 3 trough 7 of Figure 2, the chimeric RNA end product contains the entire protein coding region of a conventional mRNA and can be translated into the original, conventional mRNA-encoded, polypeptide. In the chimeric mRNA amplification pathway, the position of the TCE within the antisense molecule is always strictly 3'-terminal. In contrast, the intramolecular location of the internal ICE element is variable, and potentially it can be positioned within a segment of the antisense strand corresponding to the coding portion of an mRNA, a scenario diagrammed in steps $\mathbf{3}^{\prime}$ trough $\mathbf{7}^{\prime}$ of Figure 2. In this scenario, the chimeric RNA end product would consist of a 3'-terminal segment of the antisense strand (the TCE or its fraction) attached, in a 5' to 3 ' orientation, to a 3' portion of a conventional mRNA progenitor with a 5 '-truncated coding region. In such a case, the translational outcome would be decided by the position of the first functional (capable of initiation of translation) AUG or another translation initiation-competent codon. If it were in-frame with the proteinencoding information content of conventional mRNA, translation would result in the C-terminal fragment, CTF, of a conventionally encoded polypeptide. This variant of RNA-dependent mRNA amplification pathway would be asymmetric. Indeed, only one end, a 3-terminal portion, of conventional mRNA would be amplified, and its translation would produce only one end of a conventional genome-encoded polypeptide, its C-terminal fragment. With regard to a possible $\beta A P P$-independent production of beta-amyloid in such a manner, three crucial questions are: (1) Is human $\beta A P P$ mRNA eligible for RNA-dependent amplification? (2) If it is, does amplification occur asymmetrically? (3) If affirmative, would the N-terminus of the resulting polypeptide be precisely that of $A \beta$ ?

Asymmetric Amplification of Human BAPP mRNA May Result in the Chimeric mRNA End Product Encoding C99 Fragment of the Beta-Amyloid Precursor Protein

Potentially pivotal role of the AUG encoding Met671 in conventional human $\beta A P P$ mRNA in $\beta A P P$-independent generation of $A \beta$ in Alzheimer's disease 


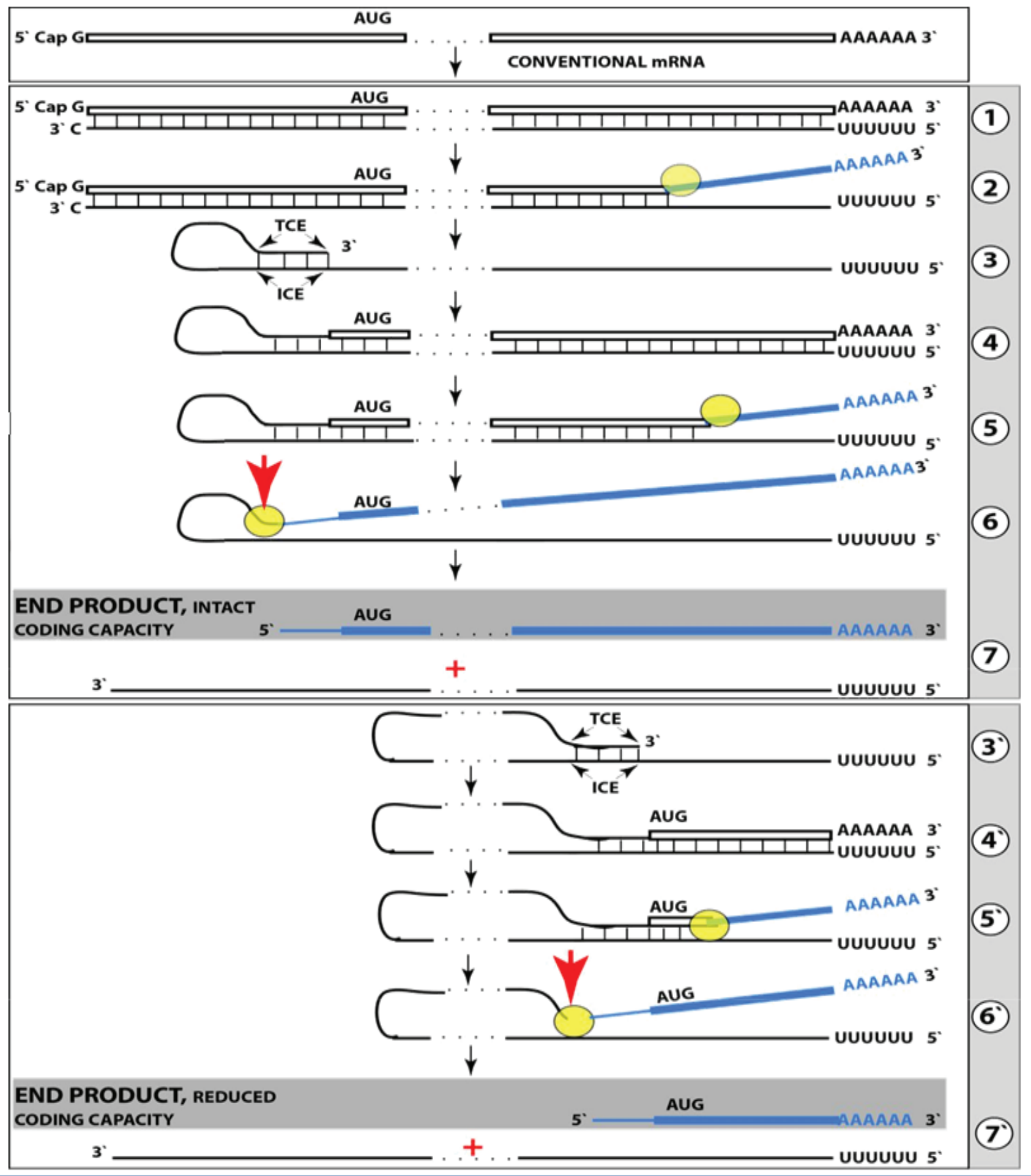

Figure 2: RNA-dependent mRNA amplification can result in a 5'-truncated molecule encoding C-terminal fragment of a conventionally encoded polypeptide. Boxed line-sense strand RNA. Single line-antisense strand RNA. "AUG"-functional translation initiation codon (could be other than AUG). "TCE"3'-terminal complementary element; "ICE"- internal complementary element, both on the antisense RNA strand. Yellow circle - helicase/ modifying activity complex. Blue lines (both single and boxed) - RNA strand modified and separated from its complement by a helicase complex. Red arrow - position of cleavage of the chimeric intermediate. Step 1: Synthesis of antisense strand; step 2: Strand separation; step 3: Folding of antisense strand into self-priming configuration; step 4: Extension of self-primed antisense RNA; step 5: Strand separation; step 6: Cleavage of the chimeric intermediate; step 7: End-products of RNA amplification. Steps 3'-7' correspond to steps 3-7. Top panel: Conventional, genome-transcribed mRNA molecule. Middle panel: Projected stages of RNA-dependent mRNA amplification. "ICE" is located within a segment of antisense RNA corresponding to the 5'UTR of conventional mRNA; the chimeric RNA end product contains the entire coding content of conventional mRNA. Bottom panel: "ICE" is located within a segment of antisense RNA corresponding to the coding region of conventional mRNA. The amplified chimeric end product contains a 5'-truncated coding region of conventional mRNA. The translational outcome is decided by position of the first functional translation initiation codon; if in-frame, a CTF of conventional polypeptide is produced. 
The answer to question (3) in the preceding section is suggested by the primary structure of the human $\beta$ APP mRNA. In this molecule, the $A \beta$-encoding segment is preceded immediately and in-frame by the AUG codon normally encoding methionine in position 671 of the $\beta \mathrm{APP}$ (isoform 770 numbering). If translation were initiated at this position, it would produce the $12 \mathrm{kDa}$ C-terminal $\beta$ APP fragment, C99 after the removal of methionine by the $\mathrm{N}$-terminal methionine aminopeptidase, independently of $\beta$ APP. Interestingly, the AUG in question is situated within a nucleotide context optimal for the initiation of translation (an "A" in position -3 and a "G" in position +4 relative to the "A" of the AUG codon). In fact, of the twenty AUG codons encoding methionine residues in the human $\beta$ APP mRNA, only the AUG encoding Met671 (not even the AUG encoding Met1) is located within an optimal translation initiation context. Such favorable positioning of the AUG encoding Met671 of $\beta$ APP was the basis for a proposal that in Alzheimer's disease, the C99 fragment of beta-amyloid precursor protein may be generated independently from $\beta A P P$ by the internal initiation of translation at the AUG encoding Met671 of the intact $\beta$ APP mRNA [92]. Such precursor-independent generation of $\mathrm{C} 99$ would be an efficient way to overproduce $\mathrm{A} \beta$. This is because (a) C99 is not susceptible to the alpha-secretase cleavage [1$3]$, and (b) cleavage by gamma-secretase was shown to be not the ratelimiting step in the production of $A \beta$ [1-3]. The possibility of internal initiation of translation, proposed by Breimer and Denny [92], has been, however, subsequently ruled out by experiments of Citron and co-investigators [93].

On the other hand, the implications of the occurrence of an AUG codon in such a position for potential $\beta$ APP-independent generation of $A \beta$ via asymmetric $\beta$ APP mRNA amplification are clear: If human $\beta$ APP mRNA is eligible for RNA-dependent amplification, if it is amplified in an asymmetric manner in $\mathrm{AD}$, and if in the resulting 5 '-truncated chimeric mRNA the first, 5'-most, functional translation initiation codon were the AUG encoding Met671 in the conventional $\beta A P P$ mRNA, the translational outcome would be the C99 fragment of amyloid precursor protein produced independently of $\beta A P P$ and containing $A \beta$ at its $\mathrm{N}$-terminus. Is such an outcome feasible?

\section{Projected pathway of asymmetric amplification of $\beta A P P$ mRNA resulting in chimeric mRNA encoding the C99 fragment of beta-amyloid precursor protein}

With regard to questions (1) and (2) formulated above, to determine if an mRNA species of interest can potentially be a subject of RNA-dependent mRNA amplification (provided that the cellular RdRs machinery is activated), one needs to assess whether its antisense complement contains both TCE and ICE and is capable of folding into a self-priming configuration. If it is, the position of the ICE will indicate the possible translational outcome. Such an assessment can be conducted in a model experiment where an mRNA of interest serves as a template for synthesis of cDNA, initiating at the 3'-terminal poly(A), and is subsequently removed by RNAse $\mathrm{H}$ activity present in a preparation of reverse transcriptase used. If an mRNA is fully transcribed, if complementary elements are present within the antisense strand (cDNA), if one of them is 3 '-terminal, and if they are topologically compatible, self-priming and the extension synthesis of a segment of the sense strand would occur. The junction between the antisense and sense components would define the site of self-priming and facilitate identification of the TCE and ICE. Just such an experiment was inadvertently carried out with human $\beta A P P$ mRNA [94]. The results of this experiment, misinterpreted and eventually dismissed by the authors as an artifact [95], indicated the occurrence of topologically compatible TCE and ICE elements within the antisense strand of $\beta$ APP mRNA and defined their sequence as well as the position of self-priming. Based on these results, the TCE/ ICE-guided folding and extension of the antisense strand of human $\beta A P P$ mRNA [70-75] can be depicted as shown in Figure 3.

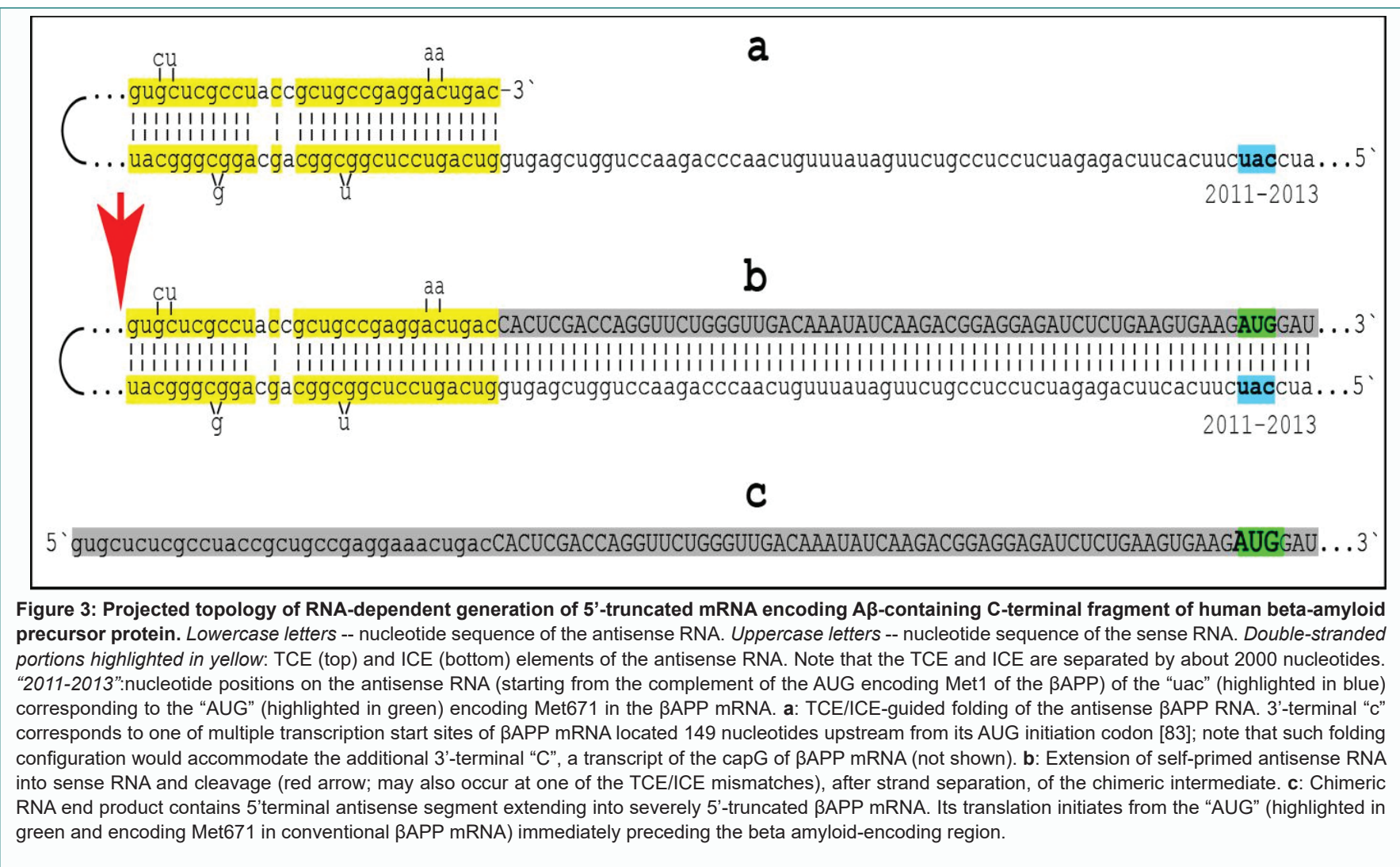


An approximately 30 nucleotide-long 3'-terminal segment of the antisense strand of $\beta A P P$ mRNA constitutes the TCE. Its counterpart, the ICE, is separated by nearly 2000 nucleotides, yet these elements are topologically compatible and the folding of the antisense molecule results in a self-priming configuration capable of accommodating the additional 3'C not encoded in the genome, a transcript of the capG of $\beta A P P$ mRNA [85-87] (Figure 3a). The TCE serves as a primer and is extended; thus generating the sense strand as shown in Figure $3 \mathbf{b}$. Strands are then separated as illustrated in Steps 5' and 6' of Figure 2 , and cleavage occurs either at the mismatches within the TCE or immediately upstream as indicated by the arrow in Figure $3 \mathbf{b}$. The resulting chimeric RNA end product, shown in Figure 3c, consists of an antisense segment (TCE or its portion) continued into a senseorientated molecule. The translational outcome is decided by the first, 5'-most, initiation-competent AUG codon. As shown in Figure $3 \mathbf{b}$ and $\mathbf{c}$, the first AUG codon is located 58 nucleotides downstream from the TCE portion of the chimeric RNA end product and it is, in fact, the AUG encoding Met671 in the intact $\beta A P P$ mRNA! Translation from this position would produce C-terminal fragment of $\beta$ APP containing beta-amyloid at its N-terminus, the C99 fragment of the beta-amyloid precursor protein, in a $\beta$ APP-independent manner. The major prediction of such a mechanism is a complete inefficiency of beta-secretase inhibition in Alzheimer's disease. This prediction was, in fact, born out in several massive stage III clinical trials [34,73].

Exclusivity of Alzheimer's Disease to Homo sapiens: In Animals, in Contrast to Humans, $\beta A P P$ mRNA is Ineligible for the RNA-Dependent Amplification Process, a Presumed Driver of the Disease

As discussed above, the presence of poly(A) at the 3' terminus of an RNA makes the molecule an eligible RdRp template, but it does not necessarily makes it eligible for amplification. For this, the antisense RNA strand should be capable of forming a stable self-priming structure in which its 3 ' terminus can be extended into a segment of the conventional mRNA molecule. Folding of the antisense RNA in such a self-priming configuration requires, in turn, the occurrence of two complementary and topologically compatible elements, one of which is strictly 3'-terminal. It appears that this requirement is not met in antisense RNA complements of $\beta A P P$ mRNA in non-human mammals. In animals, $\beta$ APP antisense RNA segments corresponding to the TCE and ICE elements of human $\beta$ APP antisense RNA show little, if any, complementarity; moreover, the 3'-terminal segment of animal antisense $\beta$ APP RNA has no extensive complementarity with the rest of the molecule. Thus, in non-human mammals, $\beta$ APP mRNA, although a suitable RdRp template by virtue of containing 3'-terminal poly(A), is not eligible for the RNA-dependent mRNA amplification process. Therefore, if, as suggested above, the extent of increase in beta-amyloid levels sufficient to trigger amyloid cascade culminating in $A D$ cannot be reached by the $\beta A P P$ proteolytic pathway alone and requires the activation of the $\beta A P P$ mRNA amplification pathway, Alzheimer's disease can occur in humans but not in animals, a conclusion consistent with observations in the field.

In most current mouse and rat models of $\mathrm{AD}$, the overproduction of $A \beta$ is forced non-physiologically by expression of multiple transgene copies of suitably modified human $\beta$ APP-encoding DNA. In many cases, the inserted DNA encodes only a 5 '-truncated portion of the $\beta$ APP gene. In such a case, even if RdRs were enabled by $\mathrm{A} \beta$-induced mitochondrial dysfunction, beta-amyloid-encoding
mRNA would not be eligible for amplification because its antisense complement would be lacking the 3'-terminal complementary element, TCE. Even when a full copy of the $\beta$ APP gene is inserted, it is in a non-physiological chromosomal location, regulated by a nonphysiological promoter, and would likely result in a non-physiological position of the Transcription Start Site, TSS. In such a case, the TCE of the antisense strand would be either absent or non-terminal; in both cases the amplification would not be feasible. In other words, betaamyloid production occurs solely by the proteolysis of beta-amyloid precursor protein in currently employed animal models of $\mathrm{AD}$, as it does in naïve animals.

Only a Subset of $\beta A P P$ mRNA Transcripts is Eligible for RNA-Dependent Amplification Process in Humans: TSSs Utilization May Contribute to Susceptibility or Resistance to Alzheimer's Disease

The presence of a regulatory element known as a "TATA-box" is characteristic for a large class of mammalian genes. Usually, it occurs about 25 nucleotides upstream from the transcription start site and rigidly defines its position. The $\beta$ APP gene belongs to a class of TATAless genes that are characterized by multiple transcription start sites. There are at least five and possibly more positions where transcription of human $\beta$ APP mRNA can be initiated $[70,96]$. Of those, only one, 149 nucleotides upstream from the AUG translation initiation codon, shown in Figure 3, results in an mRNA molecule eligible for RNA-dependent mRNA amplification process because only for this transcript would the position of TCE on its antisense strand be strictly 3'-terminal $[34,70]$, and the additional 3' $\mathrm{C}$, a transcript of the capG of $\beta A P P$ mRNA [85-87], be accommodated in the antisense RNA selfpriming structure (Figure 3). Utilization of human $\beta A P P$ transcription start sites can be, therefore, one of the factors that define susceptibility or resistance to Alzheimer's disease. The ability to regulate the usage of $\beta$ APP TSSs, or even to shift it at will, could open powerful therapeutic applications.

\section{Intracellular Retention of $\mathrm{A} \beta$ in $\mathrm{AD}$ :} Processing of C99 Produced in the Asymmetric BAPP mRNA Amplification Pathway Is Distinctly Different from that of BAPP and Apparently Neuron-Specific

Normally, proteolytic processing of the bulk of $\beta$ APP occurs in the secretory pathway and culminates in gamma-secretase cleavage within the plasma membrane and subsequent secretion of newly generated $\mathrm{A} \beta$ into extracellular space. A nascent $\beta$ APP molecule is chaperoned into the secretory pathway through its $\mathrm{N}$-terminal signal peptide. There is, however, no signal peptide in the translational end product of asymmetric amplification of human $\beta A P P$ mRNA. Indeed, the $\beta A P P$ mRNA amplification pathway results in the C99 fragment. C99 lacks $\mathrm{N}$-terminal signal peptide and requires only gamma-secretase cleavage to produce $A \beta$. This cleavage can occur on intracellular membranes at a variety of sites, such as ER and TGN [54-60], where gamma-secretase cleavage was shown to occur only in neurons [60], and even in mitochondria where all subunits of the gamma-secretase complex were shown to be present [67-69]. If this cleavage occurs in the $E R$, the $A \beta 42$ isoform will be predominantly produced [60]. If both ER and TGN sites are utilized, a mixture of $A \beta 42 / A \beta 40$ will result [60]. Since the processing of the C99 fragment expressed from a construct encoding only this polypeptide, rather than $\beta A P P$, was shown to result, due to the presence of an internal transmembrane domain, in 
secretion of $A \beta$ in a non-neuronal cell model [2], it has to be assumed that intracellular retention of $A \beta$ produced from C99-encoding $m R N A$, the end product of asymmetric $\beta A P P$ mRNA amplification, is neuron-specific. The bottom line is that for $A \beta$ to be retained intraneuronally, its precursor, the $\mathrm{C} 99$ fragment produced in the $\mathrm{AD}$ specific $\beta$ APP mRNA amplification pathway, has to be processed, i.e. cleaved by gamma-secretase, on an intracellular membrane. This is feasible. Moreover, there are multiple options, some of them neuronspecific and generating predominantly $A \beta 42$ [60], to accomplish this. In addition, if the heavily modified mRNA end product of asymmetric human $\beta$ APP mRNA amplification, encoding the C99 fragment, is translated in a compartmentalized manner, this may also contribute to selection of gamma-secretase cleavage sites on intracellular rather than plasma membranes.

\section{Engine that Drives Beta-Amyloid Overproduction and Alzheimer's Disease \\ Cellular machinery capable of RNA-dependent mRNA amplification is activated by certain types of stress}

As discussed above, the core enzymatic machinery required for RNA-dependent mRNA amplification appears to be constitutively present, albeit in a non-conventional form [79-81], in all mammalian cells. Under regular circumstances, this core RdRp activity produces only short antisense transcripts due to the lack of a processivity cofactor $[85,86]$. Our current understanding indicates that mammalian core RdRp activity is constitutively expressed and that its processivity co-factor is inducible [85,86]. It doesn't inform us on the status of other RdRs components involved, such as helicase/modifying activity and single-strand cleaving activity $[85,86]$. Inducible components of the mammalian RdRp complex appear to be expressed under special circumstances requiring a substantial overproduction of specific proteins. Their induction is likely triggered by certain types of cellular stress [85-87]. One possible example of such regulation is RNAdependent amplification of mRNA encoding secreted extracellular matrix proteins.

The occurrence of RNA-dependent amplification of mRNAs encoding all three chains of laminin was demonstrated in mouse tissue producing very large quantities of this protein [87]. Previous studies suggested [85-87] that the initial ER stress resulting from increased transcription and subsequent translation of conventional mRNAs encoding secreted proteins, such as laminin, could be one of potentially multiple cellular events that may trigger mRNA amplification. In such cases, one can envision that conventional overproduction of secreted proteins induces ER stress and activates multiple transcription factors $[97,98]$ that complement cellular core RdRp activity and stimulate RNA-dependent mRNA amplification. It could be argued that this would further exacerbate ER stress and trigger cell death. However, the amplified and heavily modified mRNA may behave in ways that are different spatially, qualitatively and quantitatively from those of conventional mRNAs. One cellular response to ER stress appears to be translation and secretion that bypasses ER even if $\mathrm{N}$-terminal signal peptide is present [99]. It is possible, therefore, that nucleotide modifications of amplified mRNA may direct its translation and secretion of the resulting protein via ERbypassing pathways, despite the presence of a signal peptide sequence. In such a case, mRNA amplification triggered by ER stress would eventually relieve the stress because the modified chimeric RNA end product and conventional mRNA molecules, used as templates for the production of antisense RNA and modified during strand separation (Figure 1, step 2), would be translationally processed outside the ER.
Mitochondrial dysfunction and related stress are possible activators of RNA-dependent $\beta$ APP mRNA amplification in Alzheimer's disease

In the case of Alzheimer's disease, a probable trigger of asymmetric RNA-dependent $\beta$ APP mRNA amplification, resulting in 5 'truncated mRNA encoding the $\mathrm{A} \beta$-containing $\mathrm{C} 99$ fragment in a precursor-independent manner, is stress of metabolic mitochondrial dysfunction [74,75]. Mitochondria are dynamic ATP-generating organelles, which contribute to many cellular functions, including bioenergetic processes, intracellular calcium regulation, alteration of reduction-oxidation potential of cells, free radical scavenging and activation of caspase-mediated cell death. There is mounting evidence showing that mitochondrial damage plays an important role in Alzheimer disease. Increased generation of oxygen species and deficient mitochondrial dynamic balance have been suggested to be the reason as well as the consequence of Alzheimer-related pathology. In $\mathrm{AD}$, mitochondrial functions can be negatively affected by beta-amyloid, which can interact with mitochondria and cause mitochondrial dysfunction, and, consequently, oxidative stress. This, in turn, mediates an increased production of $\mathrm{A} \beta$ and thus drives the disease [67-69].

Mitochondrial dysfunction is a prominent and early feature of $\mathrm{AD}$ [100], with reduced energy metabolism as one of the best documented early abnormalities [101]. Key mitochondrial enzymes of oxidative metabolism (i.e., cytochrome C oxidase, KGDHC, and PDHC) are deficient in $\mathrm{AD}[102,103]$. Early deficits in synaptic mitochondria were also detected in an AD mouse model [104]. In addition, damages of mitochondrial DNA (mtDNA), including DNA mutations and DNA defects, are also found to be involved in $\mathrm{AD}$ [105]. Both beta-amyloid precursor protein and $A \beta$ were localized in mitochondria [106$110]$, and $A \beta$ not only contributes to significant oxidative damage of mtDNA, but leads also to impaired mtDNA gene expression [111,112]. More recent studies suggest that abnormal mitochondrial dynamics, including excessive mitochondrial fragmentation and abnormal mitochondrial distribution, plays a critical role in mitochondrial dysfunction in $\mathrm{AD}$ [113-120].

How stress associated with mitochondrial dysfunction enhances the production of $A \beta$ in Alzheimer's disease remains to be elucidated. Recently, it was proposed that it activates the expression of $R d R p$ processivity co-factor and other inducible components of the $R d R p$ complex and thus enables asymmetric RNA-dependent amplification of human BAPP mRNA, overproduction of the C99 fragment, and, consequently, the overproduction of $A \beta$ [74]. This is consistent with a notion mentioned above that a substantial overproduction of $A \beta$, to the extent sufficient to activate the beta-amyloid cascade and trigger Alzheimer's disease, cannot occur without $\beta$ APP mRNA amplification. This also implies that mitochondrial dysfunction, on its own, cannot trigger Alzheimer's disease, as supported by the observation that in mice, where RNA-dependent amplification of its $\beta A P P$ mRNA cannot take place, mitochondrial dysfunction, even in long terms, results in neither a substantial $A \beta$ accumulation, nor in excessive beta-amyloid plaque formation and neurodegeneration [121]. One of the mitochondrial components, the microprotein PIGBOS, was shown to interact with the ER in mitigating the unfolded protein response (UPR) [122]. It is feasible that mitochondrial dysfunction suppresses the occurrence and/or functionality of PIGBOS; this, in turn, may lead to suppression of UPR and, consequently, to ER stress. It is therefore possible that mitochondrial dysfunction triggers the expression 
of inducible components of the RdRp complex by initiating ER stress, implicated in the activation of RNA-dependent $m R N A$ amplification pathway [87].

\section{Cause-and-effect relationships between mitochondrial dysfunction and Alzheimer's disease}

The cause-and-effect relationships between mitochondrial dysfunction and Alzheimer's disease appear to be very different, in fact diametrically opposite, in FAD and SAD. In FAD, increased levels or more toxic species of $A \beta$, the results of mutation-mediated abnormal proteolysis of $\beta$ APP, trigger metabolic mitochondrial dysfunction, augmented ROS levels and ER stress. This, in turn, activates $\beta$ APP mRNA amplification, causes the additional increase in production of $\mathrm{A} \beta$, and reinforces the cycle. Thus in FAD, mitochondrial dysfunction is an intrinsic component of the amyloid cascade. The reverse sequence is true in $\mathrm{SAD}$, where age-related mitochondrial dysfunction, mitochondria-derived reactive oxygen species, and, possibly, ER stress related to mitochondrial dysfunction activate RNA-dependent amplification of $\beta A P P$ mRNA and enhanced production of $A \beta$. This causes further mitochondrial dysfunction, the cycle repeats and degeneration increases. Thus in SAD, the initial mitochondrial dysfunction arises prior to the disease, independently of and upstream from the increased $\mathrm{A} \beta$ production. In other words, in $S A D$, in contrast to FAD, mitochondrial pathology hierarchically supersedes $A \beta$ pathology. This is the primary reason for the formulation of the Mitochondrial Cascade Hypothesis, $\mathrm{MCH}[13,14]$, but even in terms of the $\mathrm{MCH}$, the core of the disease is the amyloid cascade as defined in the $\mathrm{ACH}$ [7-12]. The role of mitochondrial dysfunction in relation to this core is causative in the case of SAD and auxiliary in FAD.

Engine that drives Alzheimer's disease: Self-perpetuating mutual $A \beta$ overproduction/mitochondrial dysfunction feedback cycles

As described above, the initial increases in levels of $A \beta$ are attained differently in different forms of Alzheimer's disease. In FAD, it is caused by mutations in and, consequently, abnormal proteolysis of $\beta A P P$ and occurs relatively early in life. In SAD, it is stimulated by an age-dependent component and takes place, accordingly, late in life. Regardless of their origin, however, upon reaching a certain threshold, elevated levels of beta-amyloid initiate, in both forms of $\mathrm{AD}$, mechanistically identical self-perpetuating mutual $A \beta$ overproduction/mitochondrial dysfunction feedback cycles that drive, via RNA-dependent $\beta$ APP mRNA amplification, $A \beta$ overproduction and are an essential element of the amyloid cascade leading to Alzheimer's disease. This explains drastic differences in the age of onset, yet profound pathological and symptomatic similarities in the progression, of familial and sporadic forms of Alzheimer's disease. These relationships are diagrammatically summarized in Figure 4; it depicts the mutual feedback cycles as a two-stroke engine, an engine that drives beta-amyloid overproduction and, consequently, Alzheimer's disease. If beta-amyloid produced by the mitochondrial dysfunction-enabled $\beta$ APP mRNA amplification pathway is retained intracellularly, once the $\beta$ APP mRNA amplification process is activated, cellular levels of $A \beta$ will sharply increase and so will the extent of $A \beta$-induced mitochondrial dysfunction, thus further intensifying mutual feedback cycles.

Alzheimer's Disorder is a Fast Disease Preventable by Therapeutic Intervention Initiated Even Late in Life, and Treatable and Reversible at the Early Stages
The present study posits that Alzheimer's disorder is a "fast" disease. This is in sharp contrast to a view, prevailing until now, that Alzheimer's disease is a quintessential "slow" disease that develops throughout the life as one prolonged process. According to this prevailing view, beta-amyloid is produced and secreted solely by the $\beta$ APP proteolytic/secretory pathway. As its extracellular levels increase, it triggers neurodegeneration starting relatively early in life. Damages accumulate and manifest, late in life in sporadic Alzheimer's disease ( $\mathrm{SAD}$ ) cases, as $\mathrm{AD}$ symptoms (Figure $5 \mathrm{~A}$ ). In familial $\mathrm{AD}$ (FAD) cases, where mutations in $\beta A P P$ gene or in presenilins increase production of either common $A \beta$ isoform or of its more toxic isoform, neurodegeneration reaches critical threshold sooner and $\mathrm{AD}$ symptoms occur earlier in life, mostly in late 40 s and 50 s (Figure 5B). There are currently no preventive $A D$ therapies but if they were available, according to this viewpoint it would be largely futile to intervene late in life in case of potential SAD or at mid-age in cases of FAD because, although AD symptoms have not yet manifested, the damage has already occurred during the preceding decades. In this paradigm, to be effective, preventive therapeutic intervention should be initiated early in life.

The outlook suggested by the present study is radically different. According to it, Alzheimer's disease evolves in two stages. The first stage is a slow process of intraneuronal beta-amyloid accumulation. It occurs via the activity of $\beta$ APP proteolytic/secretory pathway, cellular uptake of secreted $A \beta$, and retention of a fraction of $\beta$ APPderived beta-amyloid. These processes are common to Homo sapiens, including healthy humans, and to non-human mammals, and result neither in significant damage, nor in manifestation of the disease. The second stage occurs exclusively in humans, commences with the activation of the $\beta$ APP mRNA amplification pathway shortly before symptomatic onset of the disease, sharply accelerates the rate of production and the extent of intraneuronal accumulation of $A \beta$, which is not secreted but is retained intracellularly, generates significant damages, triggers $\mathrm{AD}$ symptoms, and is fast (Figure 5C and $\mathbf{D}$ ). In this paradigm, a preventive therapy for $A D$, an $A D$ "statin", would be effective when initiated at any time prior to commencement of the second stage (Figure 5E). Moreover, there are good reasons to believe that with a drug blocking $\beta$ APP-independent $A \beta$ production pathway, asymmetric $\beta A P P$ mRNA amplification, in the second stage, it would be possible not only to preempt the disease but also to stop and to reverse it even when early $\mathrm{AD}$ symptoms have already manifested. This assumption is based on observations in studies where $\mathrm{AD}$ symptoms, as well as neurodegeneration, were reversed by suppressing, via BACE inhibition, overproduction of beta-amyloid in mouse models generating $\mathrm{A} \beta$ solely by the $\beta \mathrm{APP}$ proteolytic pathway [30-32].

\section{Therapeutic Approaches for Alzheimer's Disease: Targeting the Engine}

In light of the above discussion, there are three potential therapeutic approaches to $\mathrm{AD}$, targeting either its immediate driver, the RNA-dependent $\beta A P P$ mRNA amplification process, or the second component of the "engine", mitochondrial dysfunction-related cellular stress that activates the $\beta$ APP mRNA amplification pathway. Indeed, our current understanding is that Alzheimer's pathology is not possible without $\beta A P P$ mRNA amplification; prevent this pathway and you will prevent the disease, inhibit it early in the disease, and you may reverse $A D$. One approach is to suppress enzymatic machinery of RNA-dependent mRNA amplification. Another is to interfere with amplification at the level of $\beta$ APP mRNA or its antisense RNA 


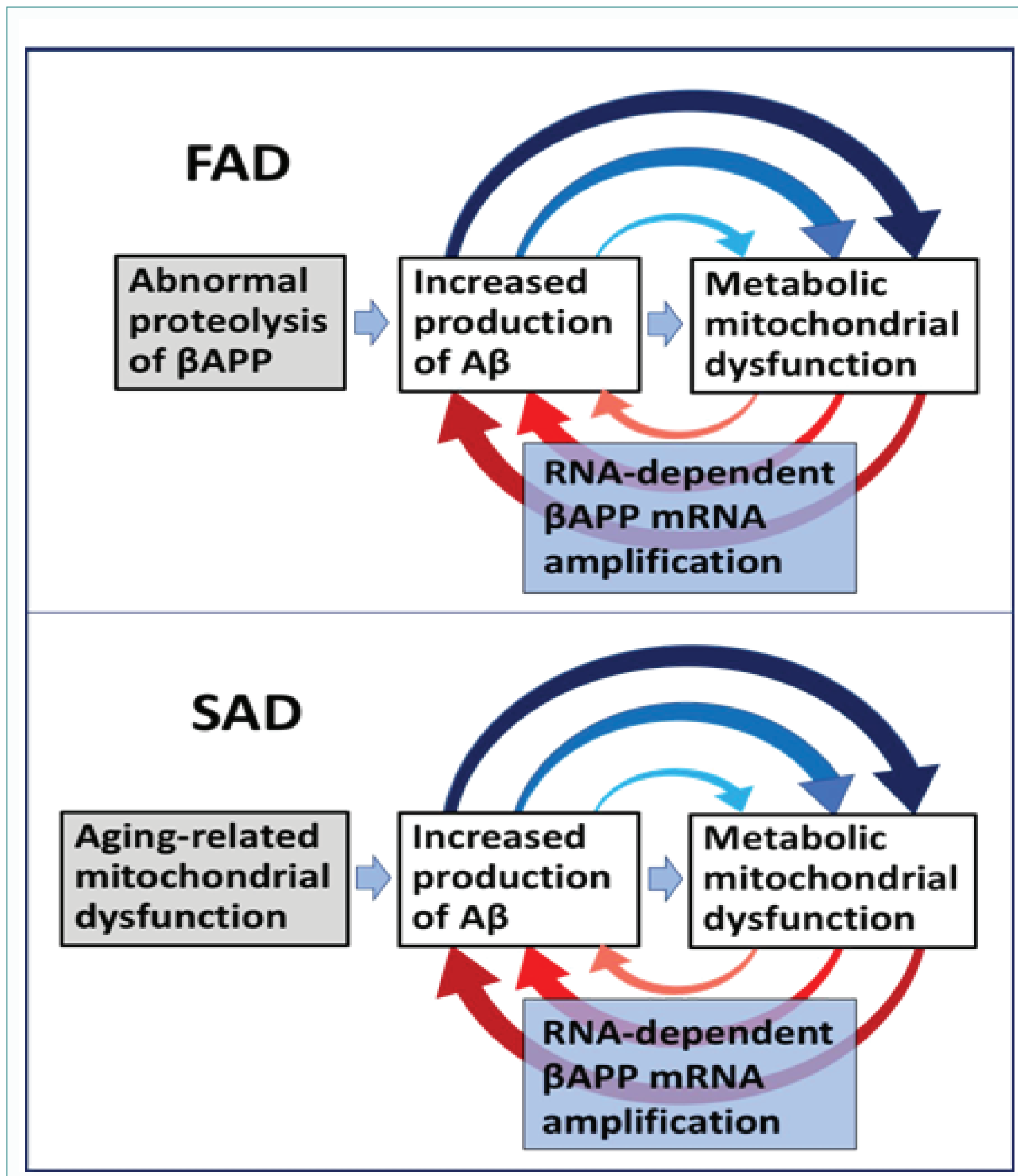

Figure 4: The engine that drives AD: Self-propagating mutual feedback cycles of mitochondrial dysfunction-mediated overproduction of beta-amyloid and vice versa in Alzheimer's disease. FAD: Familial Alzheimer's disease; SAD: Sporadic Alzheimer's disease; Highlighted in grey: Initial stimuli of the increased production of AB (different in FAD and SAD); Highlighted in blue: asymmetric RNA-dependent $\beta A P P$ mRNA amplification, a molecular basis of betaamyloid overproduction in Alzheimer's disease (note a requirement for $\beta A P P$ TSS utilization discussed in main text above); Horizontal arrows: the initial A $\beta$ overproduction cycle; Arched arrows: Mutual feedback cycles; Blue arrows: A $\beta$-mediated induction of mitochondrial dysfunction and, possibly, ER stress; Red arrows: Mitochondrial dysfunction (and, possibly, ER stress)-mediated asymmetric RNA-dependent amplification of $\beta A P P$ mRNA resulting in overproduction of A $\beta$. Note that in FAD, mitochondrial dysfunction is an intrinsic component of the amyloid cascade whereas in SAD, the initial mitochondrial pathology hierarchically supersedes and triggers $A \beta$ pathology, where self-perpetuating mutual $A \beta$ overproduction/mitochondrial dysfunction feedback cycles are, as in FAD, a central component of the amyloid cascade. In FAD, the initial increased production of $A \beta$ results from mutations-driven abnormal proteolysis of $\beta A P P$ and occurs relatively early in life, whereas in SAD, it is compelled by an aging-dependent component; hence drastic temporal difference in the age of onset yet profound pathological and symptomatic similarity in the progression of familial and sporadic Alzheimer's disease, reflecting mechanistically identical nature of feedback cycles in both forms of $A D$. 


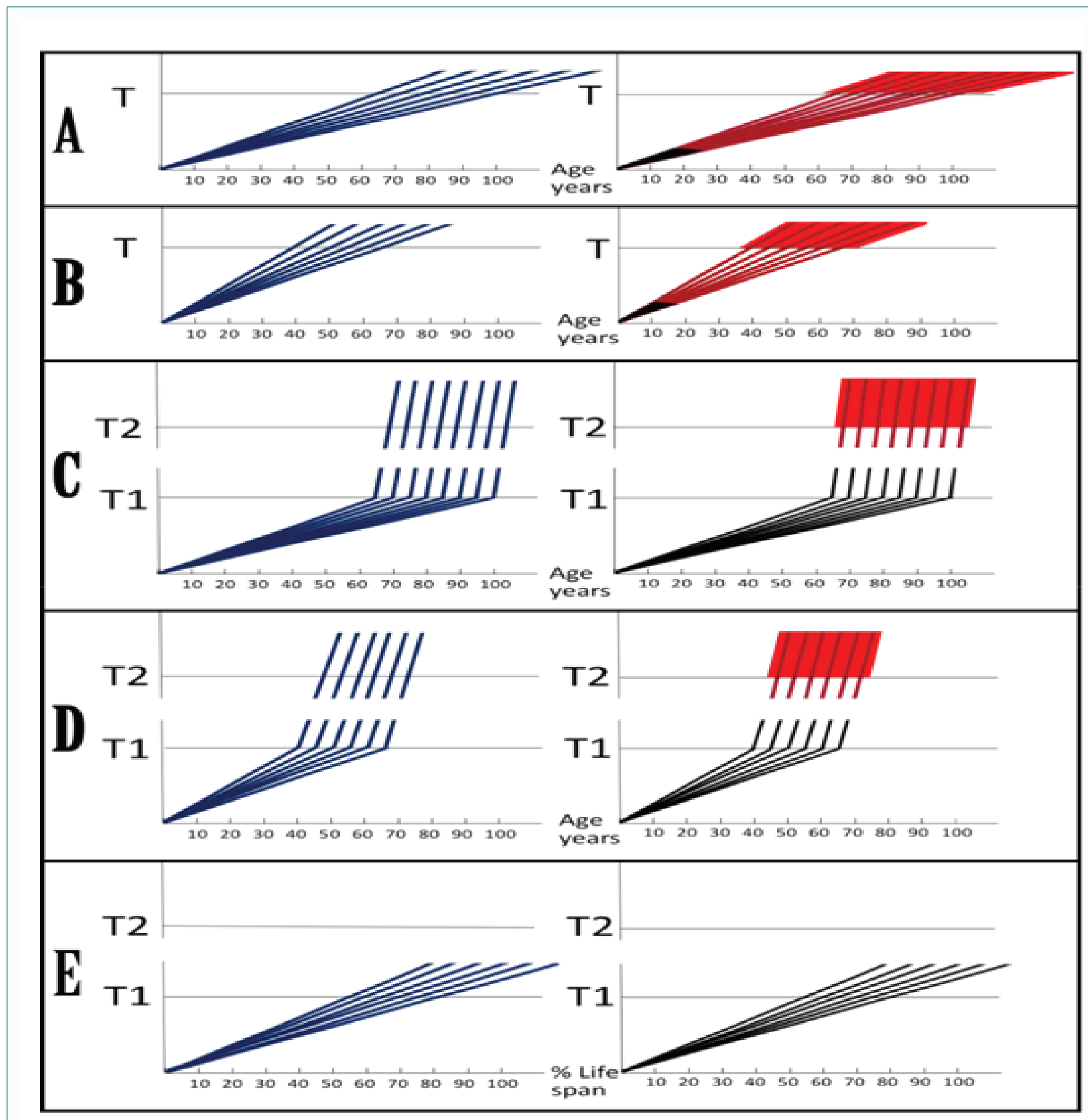

Figure 5: Dynamics of Alzheimer's disease in two paradigms. Left panels: Dynamics of A $\beta$ production; Right panels: Dynamics of neurodegeneration. Blue lines: Levels of beta-amyloid; Red lines: Extent of neurodegeneration; Black lines: Indicator lines, no significant neurodegeneration; Red blocks: Manifestation of Alzheimer's disease. T: Threshold of symptomatic manifestation of AD (reflects levels of $A B$ and consequent extent of neurodegeneration); T1: Threshold of activation of RNA-dependent $\beta$ APP mRNA amplification (reflects not only $A \beta$ levels but also the extent of $A \beta$-coupled mitochondrial dysfunction and related stresses, possibly including ER stress); Numerous genetic factors such as, for example, the occurrence of various alleles of ApoE gene, as well as certain epigenetic factors, influence the age when thresholds $T$ and $T 1$ are reached, hence, the fanning lines. T2: Threshold of symptomatic occurrence of AD (reflects levels of $A \beta$ and consequent extent of neurodegeneration). Panels $A, B$ : View of the dynamics of $A D$ prevailing until now (A: Dynamics of SAD; $\mathbf{B}$ : Dynamics of FAD). Levels of $A \beta$ increase, neurodegeneration starts early and accumulates throughout the life. When threshold $\mathbf{T}$ is reached, AD symptoms manifest. Pane/s $\boldsymbol{C}, \boldsymbol{D}$ : The outlook on the dynamics of Alzheimer's disease envisioned in the present study (C: Dynamics of SAD; $\mathbf{D}$ : Dynamics of FAD). Levels of A 3 increase, the extent of mitochondrial dysfunction and related stresses reach threshold T1 and RNA-dependent $\beta A P P$ mRNA amplification is activated. There is no significant neurodegeneration until after a lag period (when amplified RNA encoding C99 fragment of $\beta A P P$ accrues and A $\beta$ further accumulates) following the crossing of T1 threshold and activation of $\beta A P P$ mRNA amplification; when the extent of neurodegeneration reaches threshold T2, AD symptoms manifest. Panel E: Dynamics of $A \beta$ production and neurodegeneration in non-human mammals in light of the present study: T1 threshold is crossed but $\beta$ APPP mRNA is not amplified because it is not eligible for RNA-dependent amplification process. There is no significant neurodegeneration; T2 threshold is not reached, no AD symptoms manifest, no disease occurs. Note: Scenario depicted in panel (E) would occur in humans not susceptible to Alzheimer's disease due to variations in $\beta A P P$ TSSs utilization or when activation of $\beta A P P$ mRNA amplification is blocked by therapeutic intervention. 
counterpart. Third approach is to block the activation of $\beta$ APP mRNA amplification pathway by mitigating mitochondrial dysfunctionrelated stresses. First approach, suppression of RdRs enzymatic components, however tempting, is not feasible. This is because systemically targeting any component of the enzymatic machinery of RNA-dependent RNA synthesis would interfere with normal physiological functions of this process, such as, for example, specific mRNA amplification in both erythroid differentiation [84-86] and the deposition of extracellular matrix proteins [87], and would have highly deleterious consequences. Second approach, manipulation of $\beta A P P$ mRNA or of its antisense complement, is very promising. One way to do it is to shift transcription start site to such a position as to make $\beta A P P$ mRNA ineligible for the amplification process either by removing its 5 '-terminal segment corresponding to the TCE or making it non-terminal. Another way is to specifically bind a small molecule either to $\beta$ APP mRNA, in such a way as to interfere with its function as a template in antisense RNA synthesis, or to the antisense RNA in order to disrupt its folding into self-priming configuration. This approach would suppress amplification of $\beta$ APP mRNA but would not affect RdRs in general; it remains to be developed.

Third approach, suppressing activation of the $\beta A P P$ mRNA amplification pathway, is, in fact, feasible. Regardless of the initial cause-and-effect relationships between mitochondrial dysfunction and different forms of $\mathrm{AD}$, it appears that neither SAD nor FAD can occur without mitochondrial dysfunction-related stresses that enable RNA-dependent amplification of $\beta$ APP mRNA. The RNA-dependent $\beta$ APP mRNA amplification-enabling potential denotes mitochondrial dysfunction as a possible therapeutic target; this is especially important in view of the fact that success with pursuing other presumptive targets associated with the production of beta-amyloid in the proteolytic pathway has proved to be elusive. Moreover, if the aim is to pursue therapeutically RNA-dependent mRNA amplification as the plausible molecular basis of beta-amyloid overproduction in Alzheimer's disease, mitochondrial dysfunction, an ostensive trigger of this process, is the target of choice. Indeed, whereas systemic targeting of the enzymatic components of RdRs would have deleterious consequences, successfully targeting mitochondrial dysfunction would potentially result in two highly beneficial outcomes, namely, switching off the detrimental RNA-dependent $\beta A P P$ mRNA amplification process and repairing metabolic defects. In this respect, a recent study with C. elegans [123] is very encouraging. In this study, beta-amyloid-induced mitochondrial dysfunction was modeled and achieved by expressing human A $\beta$ specifically in neurons (GRU102). Importantly, treatment with an anti-diabetes drug, metformin, reversed $\mathrm{A} \beta$-induced metabolic defects, reduced protein aggregation and normalized lifespan of GRU102, thus establishing metabolic mitochondrial dysfunction as a promising and feasible therapeutic intervention target in $\mathrm{AD}$.

\section{Alzheimer's Disease: Experimental Models for Tomorrow \\ General principles}

In light of the above considerations, the current $A D$ models are inadequate because they are lacking the $\beta A P P \quad m R N A$ amplification pathway of beta-amyloid production, the major driver of the disease in humans. Since the $\beta$ APP mRNA amplification process, or rather its activation, is a major therapeutic target, conceptually new $\mathrm{AD}$ models are needed where this pathway is operational and its activation occurs in a "physiological" manner. There are two general principles that should be followed when designing experimental models for
Alzheimer's disease. First, the models should include, as their integral part, mechanisms operating in humans. In this respect, it appears that the only major beta-amyloid production pathway operating in humans, and not in current animal experimental models of $\mathrm{AD}$, is the RNA-dependent $\beta$ APP mRNA amplification process. This process fails to operate in animal models not because of the deficiencies of enzymatic machinery. There is every reason to believe that sufficient accumulation of intracellular $A \beta$, either through cellular uptake, assisted to different degrees by different ApoE isoforms, or through generation at cellular sites other than plasma membrane, or both, is capable of activating, via stress associated with mitochondrial dysfunction, the RNA-dependent mRNA amplification machinery in animal neurons just as it does in human cells, presumably via the expression of inducible components of this process. The RNAdependent $\beta$ APP mRNA amplification process fails to operate in animal models because both "naïve" and transgenically expressed $A \beta$-encoding mRNAs are, as discussed above, ineligible for the amplification process. Therefore, one objective in constructing an adequate $A D$ model is to ascertain that $A \beta$-encoding $m R N A$ is eligible for the RNA-dependent mRNA amplification process.

The second general principle in constructing $\mathrm{AD}$ models is that the activation of the A $\beta$-encoding $m R N A$ amplification pathway should occur "physiologically", i.e. through intracellular accumulation of beta-amyloid and consequent mediation of mitochondrial dysfunction and related stresses. This is important because, as discussed above, the process of activation of RNA-dependent mRNA, rather than enzymatic components of RNA-dependent mRNA amplification, is a major therapeutic target. Its recapitulation in a model would allow screening of candidate drugs. Accumulation of intracellular $A \beta$ is the rate-limiting step, a bottleneck, both in Alzheimer's disease (this is why SAD occurs late in life) and in the models of the disease. Accelerating this process is, therefore, another objective in constructing an adequate and efficient $\mathrm{AD}$ model. The most effective way to accelerate intraneuronal accumulation of $A \beta$ and thus to generate efficient models that develop symptomatic $A D$ defects in relatively short time is not, or at least not only, to overproduce it but to generate beta-amyloid in such a way that the entire output is not secreted but retained inside the cell. Moreover, the predominant production and retention of $A \beta 42$ rather than $A \beta 40$ would more efficiently lead to cellular stress capable of enabling RNA-dependent RNA synthesis. Since the activation of RdRs takes temporal precedence of the process itself, we will first address the approaches to retain newly produced $A \beta$ intraneuronally before considering possible designs of RNA-dependent amplificationeligible $A \beta$-encoding mRNA.

\section{Intraneuronal retention of newly synthesized $A \beta$ in $A D$ models}

The guidance for the retention of newly produced $A \beta$ within the cell is provided by our conclusion that beta-amyloid, produced in the asymmetric $\beta A P P$ mRNA amplification pathway, is retained intraneuronally. There are two possible reasons for this. First, amplified mRNA could be, by virtue of being heavily modified, translated, and the resulting $\mathrm{C} 99$ fragment processed, in a compartmentalized manner leading to the intracellular retention of $A \beta$. The second, more likely, reason is that asymmetrically amplified mRNA encodes the C99 fragment rather than the entire $\beta A P P$. Unlike $\beta A P P, C 99$ fragment does not contain an $N$-terminal signal peptide, does not require $\beta$-secretase cleavage, and appears to be processed, i.e. cleaved by $\gamma$-secretase, on an intracellular, rather than on the plasma, membrane. Importantly, the intracellular retention of $A \beta$ via such a process appears to be, as 
postulated above, neuron-specific [60]. Moreover, if the processing occurs within certain cellular compartments, such as the ER [5660] where $\gamma$-secretase cleavage of C99 fragment was shown to occur exclusively in neurons [60], and possibly even in mitochondria, which were shown to contain all subunits of gamma-secretase [67-69], it would result predominantly in formation of $A \beta 42$ [58-60]. Therefore, the first attempt to produce intraneuronally retained $A \beta$, possibly enriched in $A \beta 42$ isoform, should be to express it from mRNA encoding only C99 fragment rather than $\beta$ APP. If its processing resulting in intracellular retention were indeed limited to neurons due to exclusive utilization of defined cellular sites of $\gamma$-secretase cleavage [60], such an approach would be ideal for generating AD models.

There is good probability that the above approach would result in intraneuronal retention of the entire output of $A \beta$ and, consequently, in the extent of its accumulation sufficient to activate RNA-dependent mRNA amplification pathway. Short of this, or supplementary to it, various types of FAD-associated mutations could be incorporated into a design expressing the C99 fragment. These include one of several mutations resulting in preferential production of $A \beta 42$ [124127], more neurotoxic and, presumably, more efficient in facilitating the activation of mRNA amplification process, expression of ApoE4 to accelerate cellular uptake of secreted $A \beta[42,43]$, and presenilins mutations to expedite gamma-secretase cleavage at intracellular membranes and, consequently, intracellular retention of beta-amyloid $[61,62]$, rather than at the plasma membrane followed by its secretion. This approach, in addition to the approach described in the following paragraph, may become instrumental if intraneuronal retention of $A \beta$ is contingent upon compartmentalized translation of the C99 fragment from an amplified and thus modified C99-encoding $m R N A$, i.e. upon activation of the RNA-dependent mRNA amplification pathway.

It is clearly preferable to produce A $\beta$ via the processing of the C99 fragment, its immediate precursor. This is because in this case, sites of its production would be the same as those utilized in Alzheimer's disease when the asymmetric $\beta A P P$ mRNA amplification process is activated. However, in case of unforeseen difficulties, or for analyzing certain aspects of the disease, another approach to produce intracellularly retained $A \beta$ could be employed, namely to express it utilizing mRNA encoding this peptide alone rather than its precursor. One of the advantages of such an approach would be stringent control over which $A \beta$ isoform is produced. Whereas expression of $A \beta 42$ would be preferential for $\mathrm{AD}$ models, the ability to express any isoform of beta-amyloid would facilitate investigations of roles of different forms of $A \beta$ in $A D$ [128-130]. Such directly produced $A \beta$ would not be secreted but retained inside the cell. Moreover, the observed inhibition of the ubiquitin-proteasome complex by $A \beta$ [63-65] would expedite its intracellular accumulation. A concern with this approach is that cytosol-produced $A \beta$ may behave in ways that differ from those occurring in Alzheimer's disease where it is generated on intracellular membranes. Yet, even if this is the case, it could lead to mitochondrial dysfunction and associated cellular stresses that would activate the RNA-dependent mRNA amplification pathway in the same manner as it occurs in $\mathrm{AD}$.

Design of $A \beta$-encoding mRNA eligible for the RNAdependent mRNA amplification process in animal models

As was discussed above, it appears that the only major requirement for RNA to be utilized as RdRp template is the presence of 3'-terminal poly(A). This, however, does not make an mRNA eligible for amplification. The eligibility for RNA-dependent mRNA amplification is defined by the ability of its antisense RNA counterpart to form a stable self-priming structure where its 3' terminus can be extended into a segment of a conventional mRNA molecule. Folding of the antisense RNA in such a self-priming configuration requires, in turn, the occurrence of two complementary and topologically compatible elements, one of which is strictly 3'-terminal, the 3'-terminal complementary element, TCE, and the internal complementary element, ICE. Moreover, folded, self-priming configuration of the antisense RNA should be able to accommodate the additional 3'-terminal "C" not encoded in the genome but transcribed from the 5 'cap "G" of mRNA [85-87]. These requirements must be satisfied to ascertain that $A \beta$ - or C99- encoding RNA expressed in $A D$ models are eligible for the RNA-dependent $m R N A$ amplification process.

The expression of $\mathrm{A} \beta$ - or C99-encoding mRNA eligible for the amplification process can be enacted either endogenously or from a transgene. Production of A $\beta$ or of the $\mathrm{C} 99$ fragment from a modified endogenous gene and its retention intraneuronally could be sufficient for rapid accumulation of beta amyloid and consequent activation of the RNA-dependent mRNA amplification pathway. Short of this, or to further expedite the activation of mRNA amplification process, additional transgene-originated $\mathrm{A} \beta$ - or $\mathrm{C} 99$-encoding RNA would have to be expressed. These "helper" RNAs don't have to be amplificationeligible. Moreover, their ineligibility for RNA-dependent mRNA amplification process would allow to define the input and effect of RNA-dependent amplification of endogenously produced $A \beta$ - or C99- encoding mRNA. On the other hand, if endogenous $\beta$ APP gene in an animal model is incapable of producing amplification-eligible mRNA, transgene-originated A $\beta$ - or C99-encoding mRNA eligible for the RNA-dependent amplification process should be employed.

If an endogenous gene, such as murine $\beta \mathrm{APP}$, is used as a basis to generate amplification-eligible mRNAs encoding $A \beta$ or C99, we need to know the location of the predominant TSS utilized in neurons; this will define mRNA segment corresponding to the TCE of the antisense RNA. The nucleotide sequence corresponding to the ICE should precede the $A \beta$-coding portion, "humanized" by changing three amino acid residues. The TCE which will form the 5 'terminus of the resulting chimeric mRNA should not have any translation initiation codons in-frame with the $A \beta$-coding sequence, and the first AUG codon in an optimal translation initiation context should be that immediately preceding the $\mathrm{A} \beta$-coding sequence in the intact $\beta$ APP mRNA. To ensure topological compatibility of the TCE and ICE elements, they should be placed in close proximity. If the murine $\beta$ APP gene is used as a basis for the design, the about 30 nucleotide long 5 ' terminal segment of the transcript (corresponding to TCE of the antisense RNA) should be retained so as not to interfere with the location of the predominant TSS, and a matching segment (corresponding to ICE of the antisense RNA) should be inserted a short distance upstream from the $A \beta$ encoding sequence preceded by the AUG codon in an optimal translation initiation context, and the bulk of nucleotides in-between segments corresponding to the TCE and ICE should be deleted to facilitate the folding of the antisense RNA. The structure of the resulting folded antisense RNA would be conceptually similar to that depicted in Figure 3, except that the loop, instead of being about 2000-nucleotide long, would be only few nucleotides long. As shown in Figure 3, the amplified chimeric mRNA would encode the C99 fragment of $\beta$ APP. To facilitate production of $A \beta 42$ rather than $A \beta 40$, one of $F A D$-associated mutations resulting in preferential production of $\mathrm{A} \beta 42$ [124-127] could be incorporated in the design although this might not be necessary if intraneuronal 
processing of $C 99$ favors generation of $A \beta 42$ rather than $A \beta 40$ [5660]. To express directly only $A \beta$ of a defined length, the same strategy can be used with the addition of a translation termination codon at the preferred position. Endogenous expression of intraneuronally retained $A \beta$ could be sufficient to rapidly activate RNA-dependent mRNA amplification pathway. If this is not the case, additional transgene-originated $A \beta$ - or C99-encoding mRNA, not eligible for the amplification process, as discussed above, should be expressed. Ineligibility for amplification could be ascertained by eliminating from the design, or modifying, a segment corresponding to the ICE or making a segment corresponding to the TCE non-terminal in resulting mRNA.

If a transgene is utilized to express the C99 fragment or an isoform of $A \beta$ from amplification-eligible mRNA, the design is quite simple. One of multiple types of mammalian expression vectors can be used with a TATA-containing promoter and, consequently, well defined position of TSS. The 5'-terminal segment of the resulting mRNA would define the TCE of the antisense RNA, and a matching segment, corresponding to the ICE, would be placed upstream from a segment encoding either human $\mathrm{C} 99$ or a preferred human $A \beta$ isoform preceded contiguously by the AUG codon in an optimal translation initiation context; this AUG should be the first translation initiation codon in-frame with the $A \beta$-coding sequence in the chimeric RNA end product of amplification. Segments corresponding to TCE and ICE in a constructed RNA should be in close proximity to ensure topological compatibility of complementary elements within the antisense strand; the ICE element should be capable to accommodate the additional 3'-terminal "C" of the antisense RNA transcribed from the cap "G" of mRNA. As an example, murine beta-globin mRNA, that is known to be amplified during erythroid differentiation by a well understood RNA-dependent mRNA amplification mechanism [85-87], can be used as a basis for the design of a transgene expressing C99 or $A \beta$, with the globin-encoding sequence replaced with sequences encoding either human C99 or A $\beta$. PDGF, PrP or Thy- 1 promoters, all robustly driving gene expression in the central nervous system [131], or other suitable promoters can be used to express C99or $\mathrm{A} \beta$-encoding, amplification-eligible mRNAs.

A generic example of the resulting mRNA expressed from such a construct, encoding human $\mathrm{A} \beta$ or $\mathrm{C} 99$ and eligible for the RNAdependent mRNA amplification process, is presented in Figure 6. This mRNA transcript contains coding information (Figure 6A, highlighted in blue) either for the C99 fragment of human $\beta$ APP or for human $A \beta$ of a defined length preceded immediately and inframe by the AUG codon (Figure 6A, highlighted in green) in an optimal translation initiation context. Its 5 ' untranslated region, UTR, is designed in such a way that the corresponding segment of the antisense RNA contains two complementary elements, a 3'-terminal TCE and internal ICE (Figure 6B, highlighted in yellow). Accordingly, upon its formation, the antisense RNA folds into a self-priming configuration (Figure 6C). Importantly, the sequence of ICE is such that it can accommodate the additional 3'-terminal "C", not encoded in the genome but a transcript of the capG of mRNA (both 3'-terminal " $\mathrm{C}$ " and matching " $\mathrm{G}$ " at the 5 ' end of the ICE are highlighted in gray). Such a self-priming structure is then 3 '-extended (Figure 6D)

A 5' capgaUugCUUCUACAGUUGUGUUGAaACAGUACUCAACACAACCACAGAAACAAUCAUAAGAUGGAUGCAGAAUUCCGACAUGACUC . .... AAAAA3'

B $\quad 3^{\prime}$ cuaacgaagaugucaacacaacuuugucaugaguuguguuggugucuuuguuaguauucuaccuacgucuuaaggcuguacugag . ... uuuuu5'

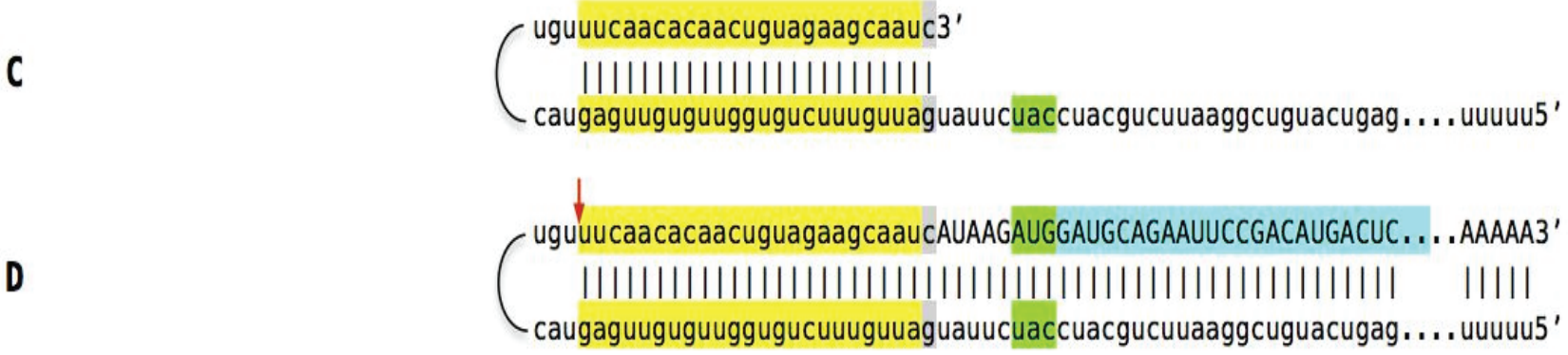

Figure 6: Example of RNA-dependent amplification-eligible mRNA encoding A $\beta$ or $C 99$ fragment of $\beta$ APP and transcribed from a transgene. Uppercase letters: Nucleotide sequence of the sense RNA. Uppercase letters: Nucleotide sequence of the sense RNA. Highlighted in blue: A $\beta$ - or C99-encoding region of mRNA. Highlighted in green: 5'AUG3' or its complement on the opposite RNA strand. Highlighted in yellow: 3'-terminal complementary element, TCE, and internal complementary element, ICE, of the antisense RNA. Highlighted in gray: 3'-terminal "C" not enoded in the DNA, a transcript of the cap" $G$ " of mRNA and matching " $G$ " at the 5' end of the ICE on the antisense RNA. Red arrow: Position of cleavage of chimeric intermediate following strand separation. A: mRNA encoding A $\beta$ or C99 fragment of BAPP. B: Antisense RNA; note that it contains additional 3'-terminal "C", a transcript of the cap" $G$ " of mRNA. C: Antisense RNA folded into self-priming configuration; note that an additional 3'-terminal "C" is accommodated by a "G" at the 5'end of the ICE. D: Extension of self-primed antisense RNA generating chimeric intermediate containing covalently bound sense and antisense RNA strands; position of cleavage following strand separation is indicated by red arrow. E: Chimeric RNA end product of RNA-dependent mRNA amplification; it consists of an antisense segment, the TCE, continued into a sense-orientation sequence containing the rest of the 5'UTR and the A 3 - or C99-coding sequence preceded by the AUG translation initiation codon and followed by the 3'UTR and 3'-terminal poly(A) 
generating sense-strand nucleotide sequence which terminates with 3 ' poly(A). This is followed by strand separation (not shown) and cleavage at the 5 ' end of the TCE (Figure 6D, red arrow). The resulting functional chimeric RNA end product of amplification (Figure 6E) consists, in its 5' portion, of an antisense segment, the TCE, continued into a sense-orientation sequence containing the rest of the 5'UTR and the $\mathrm{A} \beta$ - or $\mathrm{C} 99$-coding sequence, preceded by the AUG translation initiation codon and followed by the 3'UTR and poly(A), and can be translated into $\mathrm{A} \beta$ or $\mathrm{C} 99$ polypeptides.

\section{Cell-based AD models}

Considerations discussed above apply not only to animal models but also to potential cell-based AD models. There are, however, some marked differences: Cell-based models provide significant advantages but have also certain limitations. The major advantage is that human cells can be utilized in the design of a model. Moreover, such a model should be a neuronal one. Indeed, teratoma-derived cells [132], neuroblastoma cell lines $[133,134]$, immortalized human neural progenitor cells [135], or human induced pluripotent stem cells, iPSCs [136], could be differentiated into neuronal cells. The biggest asset of a cell based human neuronal model would be the presence of an intact endogenous $\beta A P P$ gene encoding RdRs eligible (subject to the TSS position) $\beta A P P$ mRNA. Moreover, if needed, one of several mutations resulting in preferential production of the $A \beta 42$ [124-127] could be incorporated into this gene, defined presenilins mutations could be included into a model system to expedite gamma-secretase cleavage at intracellular membranes and, consequently, intracellular retention $[61,62]$, rather than at the plasma membrane followed by secretion, or a translation termination codon could be inserted immediately following A 342 if deemed necessary.

Since in such a system, in the absence of the active RNA-dependent mRNA amplification process, $\beta$ APP mRNA, rather than C99 mRNA, will be produced, the bulk of the resulting $A \beta$ is unlikely to be retained within the cell until and unless the RNA-dependent mRNA amplification pathway is activated and the C99 fragment, rather than $\beta A P P$, is generated. If this is the case, two approaches are possible. One is to modify the endogenous $\beta$ APP gene as described above for animal models, with the exception that segments corresponding to the TCE and ICE elements are already present in human $\beta$ APP mRNA, in such a way that it will express C99-encoding, amplification-eligible mRNA. Another approach is to employ transgene-originated C99 or A $\beta$ "helpers" to facilitate intracellular accumulation of $A \beta$ and activation of the endogenous $\beta$ APP mRNA amplification. This strategy to activate RNA-dependent amplification of endogenously produced $\beta A P P$ mRNA is straightforward. In this design, C99 or A $\beta$ of the defined size can be overexpressed in chosen cells and cells induced to differentiate into neurons. For reasons discussed above, expression constructs should be such that the resulting mRNA encoding A $\beta 42$ or C99 is ineligible for RNA-dependent mRNA amplification. This can be ascertained by the absence of a functional TCE/ICE combination in the antisense RNA due either to the elimination of one of these elements or to the non terminal position of the TCE. As A $\beta$, produced either by processing of the C99 fragment or directly, will accumulate intracellularly and as its levels will reach critical threshold, mitochondrial dysfunction and cellular stresses will ensue and the endogenous $\beta$ APP mRNA amplification process would be activated.

Developing a system where AD-associated defects depend solely on the amplification of endogenously expressed A $\beta$-encoding $m R N A$ is highly desirable. Alternatively, transgene-originated mRNA encoding human $A \beta$ or $C 99$ fragment of $\beta$ APP and eligible for the RNAdependent amplification process could be designed as described above for animal models, and expressed in human neuronal cultures. In this approach, the entire output of $\mathrm{A} \beta$ or $\mathrm{C} 99$ fragment produced in neuronal cell will be retained intracellularly. $A \beta$, generated either directly, from mRNA encoding only this peptide, or, preferably, via processing of the C99 fragment, will rapidly accumulate within the cell and trigger mitochondrial dysfunction and related stresses. This, in turn, will activate the RNA-dependent mRNA amplification process. Since in such a model both, transgene transcripts and the endogenous human $\beta$ APP mRNA (subject to the TSS usage), are eligible for the amplification process, the production of $\mathrm{A} \beta$ will rapidly enter the second faze depicted in Figure 5C and its levels will sharply increase. As a result, features characteristic for $\mathrm{AD}$ would manifest.

A limitation of a cell-based AD model is that it can develop only a fraction of features characteristic for the disease. Therefore, a critical aspect in utilization of such a model is deciding what features will be evaluated in establishing its validity. On one hand, such a feature could be the occurrence of $\beta$ APP mRNA, or, more generally, A $\beta$ encoding mRNA, amplification. This can be evaluated by testing for the presence of predictable chimeric antisense/sense RNA junction sequences uniquely specific for a $\mathrm{A} \beta$-encoding mRNA being amplified in the RNA-dependent mRNA amplification process. This feature, or rather its inhibition, could also be a criteria of success in testing candidate drugs. On the other hand, one can look for a physiological feature integrally associated with $\mathrm{AD}$ pathology, such as formation of neurofibrillary tangles, NFTs. If the occurrence of NFTs is achieved in a model, its prevention or reversal could be used as an additional criteria in assessment of candidate drugs. But can it be accomplished in a cell-based model?

The answer appears to be affirmative and can be illustrated by outcomes of the "Alzheimer's in the dish" experiment [137]. In this experiment, human neural progenitor cells, immortalized by retroviral transduction with the v-myc oncogene, were used to overexpress $A \beta$ from lentiviral constructs containing human $\beta$ APP harboring multiple types of FAD-associated mutations. For reasons discussed above, $A \beta$ encoded by the expression constructs was produced only in the $\beta$ APP proteolytic pathway. PSEN1 containing FAD-associated mutation was also overexpressed in these cells, and cells were induced to differentiate in matrigel $3 \mathrm{D}$ culture medium that minimized diffusion of secreted $A \beta$ [137]. Using this approach, it was shown that cells sequentially formed extracellular $A \beta$ deposits and developed NFTs [137]. Importantly, suppression of $A \beta$ production by beta- or gamma-secretase inhibitors attenuated NFTs formation, further affirming the amyloid hypothesis of the origin of $\mathrm{AD}$, which proposes that accumulation of $A \beta$ drives tauopathy. In light of the present study, these observations can be interpreted as follows. Intracellular $A \beta$ rapidly accumulates in this system. Accumulation is driven by two sources: (a) Massive amounts of secreted $A \beta$ (mostly $A \beta 42$ ) does not diffuse into the gel medium, and part of it, primarily $\mathrm{A} \beta 42$, is internalized by cells, probably with ApoE mediation, and (b) Mutated PSEN facilitates production of $A \beta$ on intracellular membranes; these molecules are retained inside the cell. Increased levels of intracellular $A \beta$ result in the inhibition of the ubiquitinproteosome system and facilitation of the build-up of tau protein and formation of NFTs [63-66]. In this system, there is a possibility that increased levels of intracellular $A \beta$ trigger RNA-dependent amplification of the endogenously expressed $\beta A P P$ mRNA, and this is the primary cause of NFTs. Whether this is the case and, if so, what 
the role of amplified $\beta$ APP mRNA in development of NFTs may be remains to be established. This requires rigorous controls described in the following section. The results of the "AD in the dish" experiment confirm the feasibility of utilization of NFTs formation as a criteria in cell-based experimental models suggested by the present study. Since in these models the bulk of $A \beta$ will not be secreted but retained intracellularly, cells could be maintained in a regular liquid medium. It should be emphasized that a cell-based model, when available, will allow relatively easy testing of candidate drugs designed to interfere not only with the activation of the $\beta A P P$ mRNA amplification pathway but also with its eligibility for the amplification process.

\section{Controls/baseline references are essential to attune the experimental $A D$ models and to interpret the results}

Intracellular retention of conventionally produced $A \beta$ in either animal or cell-based experimental models may be excessively efficient and obscure the role of the $\beta$ APP mRNA amplification pathway in the development of $\mathrm{AD}$ or in the particular aspects of the disease. Therefore, the baseline reference is crucially needed to interpret the results. Such reference/control would be a system identical in every respect to an experimental model except that the capacity of $A \beta$ - or $C 99$ or human $\beta A P P$-encoding $m R N A$ to be amplified, i.e. its eligibility for the RNA-dependent mRNA amplification process, has been eliminated using TCE/ICE interference approaches. This means either removing or modifying a segment of mRNA corresponding to the TCE or ICE of the antisense RNA, or rendering a segment of mRNA corresponding to the TCE of the antisense RNA non-terminal. In systems, either animal- or cell-based, devised for amplification of only endogenous $A \beta$-encoding mRNA, transgenically expressed $A \beta$-encoding mRNA is designed to be ineligible for the amplification process. In such systems, therefore, the proper reference/control is to disable the amplification capacity of endogenously expressed $A \beta$-encoding mRNA as described above. Such control systems are not only essential in interpreting experimental results but also indispensable in attuning the models by titrating and adjusting levels of conventional expression of $A \beta$-encoding transgenes in such a way as to maximize the input of RNAdependent amplification of $A \beta$ - or C99-encoding mRNA.

\section{Experimental models expressing $A \beta$ solely through RNA-} dependent amplification of $A \beta$ - or C99-encoding mRNA

In models described above, it is essential to distinguish between conventionally produced beta-amyloid and $\mathrm{A} \beta$ generated in the RNAdependent amplification pathway, hence the necessity of specialized control models where the latter is suppressed. On the other hand, it is possible to design an experimental model where conventional production of beta-amyloid is bypassed and A $\beta$ or C99 are produced solely in the RNA-dependent mRNA amplification pathway. Two examples of expression constructs for such a model are presented below. In one, the AUG codon immediately preceding the human $A \beta$ - or C99-coding segment (Figure 7, top panel, line A, highlighted in blue) in endogenous human $\beta A P P$ gene is deleted and replaced by the "ACA" (its antisense counterpart, 3'ugu5', being able to accommodate 5'aug3' in the folded self-primed antisense RNA, as shown in Figure 7 , top panel, line $\mathbf{C}$ ). There is also no functional translation initiation codon in-frame with and upstream from the $A \beta$-coding segment. RNA transcribed from such a construct contains $A \beta$ - or C99-coding information but it cannot be translated into a polypeptide (Figure 7 , top panel, line $\mathbf{A}$ ). The construct is designed in such a way that this AUG-deficient, A $\beta$ - or C99-encoding RNA is nevertheless eligible for amplification if and when RNA-dependent amplification process is activated. Its antisense RNA transcript contains 3'-terminal TCE and internal ICE sequences (highlighted in yellow). Moreover, the TCE contains 5'aug3' codon (highlighted in green and shown in $3^{\prime}$ to $5^{\prime}$ orientation) in an optimal translation initiation context (Figure 7, top panel, line B). Following folding into a self-priming configuration (Figure 7, top panel, line $\mathbf{C}$ ), the structure is extended, strands are separated as described above and cleaved (red arrow) at the 5' end of the TCE (Figure 7, top panel, line D). In the chimeric RNA end product of amplification (Figure 7, top panel, line E), the TCE-derived "aug" codon, highlighted in green, ends up immediately and contiguously upstream from the $\mathrm{A} \beta$ - or C99-coding sequence (highlighted in blue) and can initiate its translation. It should be noted that in this design, the antisense strand contains not only 5'AUG3' but also a segment of $A \beta$-coding sequence at its 3 ' terminus. This is to ascertain that the additional 3'-terminal " $\mathrm{C}$ " of the antisense RNA, not encoded in the genome but a transcript of the 5'cap "G" of the sense-strand RNA [85-87], could be accommodated in the folded selfpriming configuration (both 3'-terminal " $\mathrm{C}$ " of the antisense RNA and matching " $G$ " at the 5' end of the ICE are highlighted in gray). Consequently, in the chimeric RNA end product (Figure 7, top panel, line $\mathbf{E})$, the antisense portion encodes the "aug" translation initiation codon and the $\mathrm{N}$-terminus of the resulting polypeptide (A $\beta$ or $\mathrm{C} 99$ ), whereas the sense RNA portion encodes the rest of a polypeptide and contains 3'UTR and 3'poly(A). If such a construct is incorporated into a cell or an animal where the $\beta$ APP gene was knocked out or made incapable of expressing $A \beta$, beta-amyloid will be produced, directly or through the processing of the C99 fragment, only if and when the RNA-dependent mRNA amplification process is activated.

Another example of a construct for an experimental model expressing beta-amyloid or C99 only in the RNA-dependent mRNA amplification pathway is presented in the bottom panel of Figure 7. mRNA transcribed from this construct (Figure 7, bottom panel, line A) is eligible for RNA-dependent amplification since its antisense RNA counterpart (Figure 7, bottom panel, line B) contains both 3'- terminal TCE and internal ICE (highlighted in yellow) and its folding produces a self-priming structure that accommodates the additional 3'-terminal "C" transcribed from the cap"G" of mRNA (Figure 7, bottom panel, line C; both 3'-terminal " $C$ " of the antisense RNA and matching " $G$ " at the 5 ' end of the ICE are highlighted in gray). Sense-strand mRNA contains human A $\beta$ - or C99-coding information (highlighted in blue) immediately preceded by the AUG codon, highlighted in green (Figure 7 , bottom panel, line A), just as in endogenous human $\beta$ APP mRNA. Yet, this information cannot be translated into $A \beta$ or $C 99$ because upstream is another AUG (highlighted in red), in an optimal translation initiation context, inserted out-of frame with the $A \beta$-encoding sequence, and it is this AUG that will initiate the translation (Figure 7, bottom panel, line A). However, if the upstream AUG highlighted in red (Figure 7, bottom panel, line $\mathbf{A}$ ) is placed within a segment of mRNA corresponding either to the TCE, or to the loop region of folded antisense RNA as shown in the bottom panel of Figure 7, or even to the ICE, provided its complement's (3'uac5' in the antisense RNA) match in the TCE would not be 5'aug3', it would, after strand separation and cleavage indicated by red arrow (Figure 7, bottom panel, line D), be lost in the chimeric RNA end product of amplification (Figure 7, bottom panel, line $\mathbf{E}$ ), which would retain only the AUG contiguously preceding the $A \beta$-coding sequence and could be translated into $A \beta$ or C99 polypeptides. When incorporated into cells that cannot express $A \beta$ endogenously or into an animal such as $\beta$ APP k/o mouse, such a construct would direct expression of $A \beta$ or $C 99$ only when the RNA amplification process has been activated. 


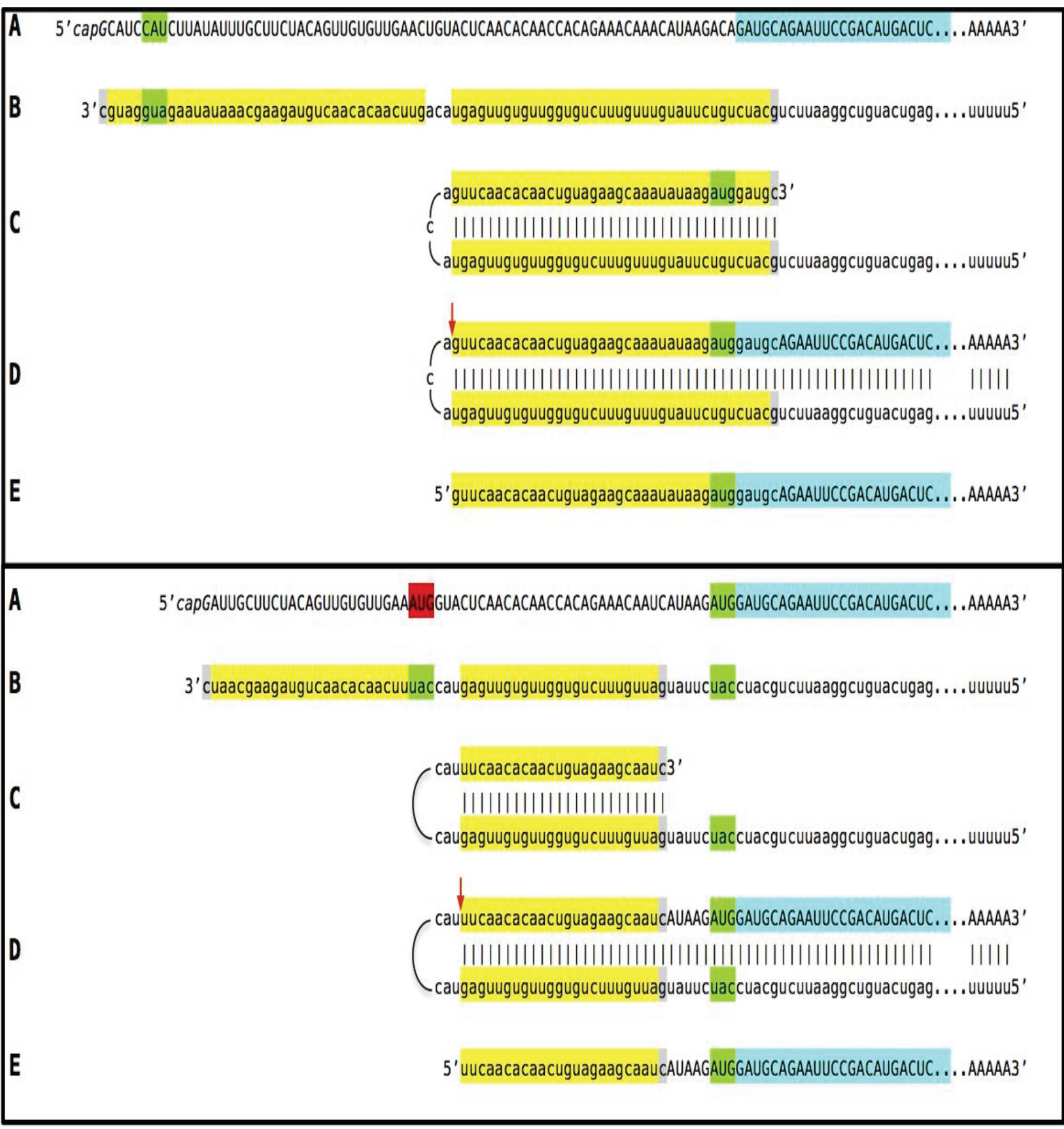

Figure 7: Design of RNA transcripts in experimental models expressing $A \beta$ solely through RNA-dependent amplification of A $\beta$ - or C99-encoding mRNA Uppercase letters: Nucleotide sequence of the sense RNA. Lowercase letters: Nucleotide sequence of the antisense RNA. Highlighted in blue: A $\beta$ - or C99encoding region of mRNA. Highlighted in green: 5'AUG3' or its complement on the opposite RNA strand. Highlighted in yellow: 3'-terminal complementary element, TCE, and internal complementary element, ICE, of the antisense RNA. Highlighted in gray: 3'-terminal "C" not enoded in the DNA, a transcript of the cap"G" of mRNA and matching "G" at the 5' end of the ICE on the antisense RNA. Highlighted in red: Additional "AUG" codon in optimal translation initiation context, upstream of and out-of-frame with A $\mathrm{B}$-encoding sequence. Red arrow: Position of cleavage of chimeric intermediate following strand separation. Top panel: A - RNA encoding $A \beta$ or $C 99$ fragment of $\beta A P P$; note that the "AUG" immediately preceding A -coding sequence has been removed and replaced by the "ACA", and there is no functional translation initiation codon in-frame with and upstream from A $\beta$-coding segment. B - Antisense RNA; note that it contains 5'aug3' followed in the 3' direction by sequence encoding $\mathrm{N}$-terminus of $\mathrm{A} \beta$ at its $3^{\prime}$ 'end. $\mathrm{C}$ - Antisense RNA folded into self-priming configuration; note that 5'aug $3^{\prime}$ is accommodated by the 3'ugu5', a complement of the "ACA" in the sense strand. D - Extension of self-primed antisense RNA generating chimeric intermediate containing covalently bound sense and antisense RNA strands; position of cleavage following strand separation is indicated by red arrow. E - Chimeric RNA end product of RNA-dependent mRNA amplification; note that it consists of the antisense portion encoding the "aug" translation initiation codon and the N-terminus of resulting polypeptide (A $B$ or C99), whereas the sense RNA portion encodes the rest of a polypeptide and contains 3'UTR and 3'-terminal poly(A). Bottom panel: A - RNA encoding A fragment of $\beta A P P$; note that it is preceded immediately by the "AUG" but also contains additional "AUG" codon in optimal translation initiation context, upstream of and out-of-frame with A $\beta$ - or C99-encoding sequence. B - Antisense RNA. C - Antisense RNA folded into selfpriming configuration. D - Extension of self-primed antisense RNA generating chimeric intermediate; position of cleavage following strand separation is indicated by red arrow. $\mathrm{E}$ - Chimeric RNA end product of RNAdependent mRNA amplification; note that it contains only one "AUG" translation initiation codon immediately preceding A $\beta$ - or C99-coding sequence followed by the 3'UTR and 3'-terminal poly(A). 


\section{Conclusion}

A view of the origin and progression of Alzheimer's disease prevailing until now and formalized as the Amyloid Cascade Hypothesis theory, maintains that the disease is initiated by overproduction of beta-amyloid, which is generated solely by the betaamyloid precursor protein proteolytic pathway and secreted from the cell. Consequent extracellular accumulation of $A \beta$ triggers a cascade of molecular and cellular events leading to neurodegeneration that starts early in life, progresses as one prolonged process, builds up for decades, and culminates in symptomatic manifestations of the disease late in life. In this paradigm, a time window for commencement of therapeutic intervention is small and accessible only early in life.

The outlook introduced in the present study is fundamentally different. It posits that the $\beta \mathrm{APP}$ proteolytic/secretory pathway of $\mathrm{A} \beta$ production causes $\mathrm{AD}$ in humans no more than it does in either shortor long-lived non-human mammals that share this pathway with humans, accumulate beta-amyloid as they age, but do not develop the disease. Alzheimer's disease, according to this outlook, is driven by an additional powerful $A D$-specific pathway of $A \beta$ production that operates in affected humans, is completely independent of the $\beta A P P$ precursor, and is not available in non-human mammals. The role of the $\beta A P P$ proteolytic pathway in the disease is activation of the additional ADspecific $A \beta$ production pathway. This occurs through accumulation of intracellular $A \beta$, primarily via ApoE-assisted cellular uptake of secreted beta-amyloid, but also through intraneuronal retention of a fraction of $A \beta$ produced in the $\beta$ APP proteolytic pathway. With time, accumulated intracellular $A \beta$ triggers mitochondrial dysfunction. In turn, cellular stresses associated with mitochondrial dysfunction, including ER stress, activate a second, $\mathrm{AD}$-specific, $\mathrm{A} \beta$ production pathway: Asymmetric RNA-dependent $\beta A P P$ mRNA amplification; it does not operate in non-human mammals because animal $\beta A P P$ mRNA is ineligible for this process.

In the asymmetric RNA-dependent $\beta$ APP mRNA amplification pathway, every conventionally produced $\beta A P P$ mRNA molecule serves potentially as a template for production of severely 5 '-truncated mRNA encoding not the $\beta A P P$ but its C99 fragment (hence "asymmetric"), the immediate precursor of $A \beta$. Thus produced, N-terminal signal peptide-lacking C99 is processed, i.e. cleaved by gamma-secretase, not in the secretory pathway on the plasma membrane but on intracellular membranes, apparently in a neuron-specific manner. The resulting $A \beta$ is, therefore, not secreted but is retained intraneuronally and accumulates rapidly within the cell. Increased levels of intracellular $A \beta$ augment mitochondrial dysfunction, which, in turn, sustains the activity of the $\beta A P P$ mRNA amplification pathway. These selfpropagating mutual $A \beta$ overproduction/mitochondrial dysfunction feedback cycles constitute a formidable two-stroke engine, an engine that drives Alzheimer's disease.

The present outlook envisions Alzheimer's disorder as a two-stage disease. The first stage is a slow process of intracellular beta-amyloid accumulation. It results neither in significant neurodegenerative damage, nor in manifestation of the disease. The second stage commences with the activation of the $\beta A P P$ mRNA amplification pathway shortly before symptomatic onset of the disease, sharply increases the rate of $A \beta$ generation and the extent of its intraneuronal accumulation, produces significant damages, triggers $\mathrm{AD}$ symptoms, and is fast. In this paradigm, the time window of therapeutic intervention is wide open, and preventive treatment can be initiated at any time, even late in life, prior to commencement of the second stage of the disease. Moreover, there are good reasons to believe that with a drug blocking the $\beta$ APP mRNA amplification pathway, it would be possible not only to preempt the disease but also to stop and to reverse it even when early $\mathrm{AD}$ symptoms have already manifested.

There are currently numerous experimental models of $\mathrm{AD}$, all based on a notion of the exceptionality of $\beta$ APP proteolytic/secretory pathway in $A \beta$ production in the disease. However, with no drug even remotely effective in Alzheimer's disease, a long list of candidate drugs that succeeded remarkably in animal models, yet failed utterly in human clinical trials of potential AD drugs, attests to the inadequacy of currently employed AD models. The concept of a renewable supply of beta-amyloid, produced in the $\beta A P P$ mRNA amplification pathway and retained intracellularly in Alzheimer's disease, explains spectacular failures of both BACE inhibition and A $\beta$-immunotherapy in human clinical trials. This concept also forms the basis of a new generation of animal and cell-based experimental models of $A D$, described in the present study. These models incorporate $\mathrm{A} \beta$ - or C99-encoding mRNA amplification pathways of beta-amyloid production, as well as intracellular retention of their product, and can support not only further investigation of molecular mechanisms of $\mathrm{AD}$ but also screening for and testing of candidate drugs aimed at therapeutic targets suggested by the present study.

\section{Authors Contributions}

VV conceived and developed all concepts outlined in this Perspective article, as well as methods of and approaches for generation of animal and cell-based models of Alzheimer's disease described in the present study, and wrote the manuscript. SR contributed to development of the concepts and to design of $\mathrm{AD}$ models. $\mathrm{BO}$ participated in discussions not related to the design of $\mathrm{AD}$ models and to the methods of their construction described in the present study.

\section{Funding}

NIH R21 GM056179; NIH RO1 AR036819.

\section{Conflict of Interest}

Authors declare no conflict of interest.

\section{References}

1. Haass C, Lemere C, Capell A, Citron M, Seubert P, Schenk D, et al. The Swedish mutation causes early-onset Alzheimer's disease by beta-secretase cleavage within the secretory pathway. Nat Med. 1995;1(12):1291-6.

2. Dyrks T, Dyrks E, Monning U, Urmoneit B, Turner J, Beyreuther, K. Generation of beta A4 from the amyloid protein precursor and fragments thereof. FEBS Let. 1993;335(1):89-93.

3. Iizuka T, Shoji M, Kawarabayashi T, Sato M, Kobayashi T, Tada N, et al. Intracellular generation of amyloid beta-protein from amyloid beta-protein precursor fragment by direct cleavage with beta- and gamma-secretase. Biochem Biophys Res Commun. 1996;218(1):238-42.

4. DeStrooper B, Annaert W. Proteolytic processing and cell biological functions of the amyloid precursor protein. J Cell Sci. 2000;113:1857-70.

5. Barber R. The genetics of Alzheimer's disease. Scientifica. 2012.

6. Vassar R. BACE1 inhibitors drugs in clinical trials for Alzheimer's disease. Alzheimer's Res Ther. 2014;6:89.

7. Beyreuther K, Masters C. Amyloid precursor protein (APP) and beta A4 amyloid in the etiology of Alzheimer's disease: precursor-product relationships in the derangement of neuronal function. Brain Pathol. 1991;1(4):241-51.

8. Hardy J, Allsop D. Amyloid deposition as the central event in the aetiology of Alzheimer's disease. Trends Pharmacol Sci. 1991;12(10):383-8.

9. Selkoe D. The molecular pathology of Alzheimer's disease. Neuron. 1991;6(4):487-98. 
10. Hardy J, Higgins G. Alzheimer's disease: the amyloid cascade hypothesis. Science. 1992;256(5054):184-5.

11. Hardy J, Selkoe D. The amyloid hypothesis of Alzheimer's disease: progress and problems on the road to therapeutics. Science. 2002;297(5580):353-6.

12. Selkoe D, Hardy J. The amyloid hypothesis of Alzheimer's disease at 25 years. EMBO Mol Med. 2016;8(6):595-608.

13. Swerdlow R. Mitochondria and mitochondrial cascades in Alzheimer's disease. J Alz Dis. 2018;62(3):1403-16.

14. Hunter S, Brayne C. Understanding the roles of mutations in the amyloid precursor protein in Alzheimer disease. Mol Psych. 2018;23(1):81-93.

15. Zhang S, Wang Z, Cai F, Wu Y, Zhang J, Song W. BACE1 Cleavage Site Selection Critical for Amyloidogenesis and Alzheimer's Pathogenesis. J Neurosci. 2017;37(29):6915-25.

16. Vassar R, Bennett B, Babu-Khan S, Kahn S, Mendiaz E, Denis P, et al. Beta-secretase cleavage of Alheimer's amyloid precursor protein by the transmembrane aspartic protease BACE. Science. 1999;286(5440):735-41.

17. Hussain I, Powell D, Howlett D, Tew D, Meek T, Chapman C, et al. Identification of novel aspartic protease (Asp2) as beta secretase. Mol Cell Neurosci. 1999;14(6);419-27.

18. Sinha S, Anderson J, Barbour R, Basl G, Caccavello R, Davis D, et al. Purification and cloning of amyloid precursor protein beta secretase from human brain. Nature. 1999, 402:537-540.

19. Wang Y, Strickland C, Voigt J, Kennedy M, Beyer B. Application of fragment-based NMR screening, X-ray crystallography, structure-based design, and focused chemical library design to identify novel $\mu \mathrm{M}$ leads for the development of nM BACE-1 inhibitors. J Med Chem. 2010;53(3):942-50.

20. Zhu Z, Sun Z, Ye Y, Voigt J, Strickland C, Smith E, et al. Discovery of cyclic acylguanidines as highly potent and selective $\beta$-site amyloid cleaving enzyme (BACE) inhibitors: Part I - inhibitor design and validation. J Med Chem. 2010;53(3):951-65.

21. Cumming J, Smith E, Wang L, Misiaszek J, Durkin J, Pan J, et al. Structure based design of iminohydantoin BACE1 inhibitors: identification of an orally available, centrally active BACE1 inhibitor. Bioorg Med Chem Lett. 2012;22(7):2444-9.

22. Edwards P, Albert J, Sylvester M, Aharony D, Andisik D, Owen C, et al. Application of fragment-based lead generation to the discovery of novel, cyclic amidine $\beta$-secretase inhibitors with nanomolar potency, cellular activity, and high ligand efficiency. J Med Chem. 2007;50(24):5912-25.

23. Barrow J, Stauffer S, Rittle K, Ngo P, Yang Z, Selnick H, et al. Discovery and X-ray crystallographic analysis of a S-piropiperidine iminohydantoin inhibitor of $\beta$-secretase. J Med Chem. 2008;51(20):6259-62.

24. Malamas M, Erdei J, Gunawan I, Turner J, Hu Y, Wagner E, et al. Design and synthesis of 5,5'-disubstituted aminohydantoins as potent and selective human $\beta$-secretase (BACE1) inhibitors. J Med Chem. 2010;53(3):1146-58.

25. Rueeger H, Rondeau J, McCarthy C, Moebitz H, Tintelnot-Blomley M, Neumann U, et al. Structure based design, synthesis and SAR of cyclic hydroxyethylamine (HEA) BACE-1 inhibitors. Bioorg. Med Chem Lett. 2011;21(7):1942-7.

26. Probst G, Xu Y. Small-Molecule BACE1 Inhibitors: a patent literature review (2006-2011). Expert Opin. Ther Patents. 2012;22:511-40.

27. May P, Dean R, Lowe S, Martenyi F, Sheehan S, Boggs L, et al. Robust central reduction of amyloid- $\beta$ in humans with an orally available, non-peptidic $\beta$-secretase inhibitor. J Neurosci. 2011;31(46):6507-16.

28. Stamford A, Scott J, Li S, Babu S, Tadesse D, Hunter R, et al. Discovery of an orally available, brain penetrant BACE1 inhibitor that affords robust CNS A $\beta$ reduction. ACS Med Chem Lett. 2012;3:897-902.

29. Kennedy M, Stamford A, Chen X, Cox K, Cumming J, Dockendorf M, et al. The BACE1 inhibitor verubecestat (MK-8931) reduces CNS $\beta$-amyloid in animal models and in Alzheimer's disease patients. Sci Transl Med. 2016;8:363ra150.

30. Keskin A, Kekuš M, Adelsberger H, Neumann U, Shimshek D. BACE inhibitiondependent repair of Alzheimer's pathophysiology. Proc Natl Acad Sci USA.
2017;114(32):8631-6.

31. Neumann U, Rueeger H, Machauer R, Veenstra S, Lueoend R, Peter S, et al. A novel BACE inhibitor NB-360 shows a superior pharmacological profile and robust reduction of amyloid- $\beta$ and neuroinflammation in APP transgenic mice. Mol Neurodegen. 2015;10:44.

32. Hu X, Das B, Hou H, He W, Yan R. BACE1 deletion in the adult mouse reverses preformed amyloid deposition and improves cognitive functions. J Exp Med. 2018;215(3):927-40.

33. Nativio R, Donahue G, Berson A, Lan Y, Amlie-Wolf A, Tuzer F, et al. Dysregulation of the epigenetic landscape of normal aging in Alzheimer's disease. Nat Neurosci. 2018;21(4):497-5050.

34. Egan M, Kost J, Tariot P, Paul SA, Yuki M, Erin M, et al. Randomized trials of verubecestat for mild-to-moderate Alzheimer's disease. $\mathrm{N}$ Engl J Med. 2018;378(18):1691-703

35. Oddo S, Billings L, Kesslak J, Cribbs D, LaFerla F. A $\beta$ immunotherapy leads to clearance of early, but not late, hyperphosphorylated tau aggregates via the proteasome. Neuron. 2004;43(5):321-32.

36. LaFerla F, Green K, Oddo S. Intracellular amyloid-beta in Alzheimer's disease. Nat Rev Neurosci. 2007;8(7):499-509.

37. Blurton-Jones $\mathrm{M}$, Laferla F. Pathways by which $\mathrm{A} \beta$ facilitates tau pathology. Curr Alzheimer Res. 2006;3(5):437-48.

38. Gouras G, Julia T, Jan N, Bruno V, Mark E, Norman RR, et al. Intraneuronal A $\beta 42$ accumulation in human brain. Am J Pathol. 2000;156(1):1520.

39. Takahashi R, Teresa AM, Feng L, Ellen EN, Mark AE, Paul G, et al. Intraneuronal Alzheimer $\mathrm{A} \beta 42$ accumulates in multivesicular bodies and is associated with synaptic pathology. Am J Pathol. 2002;161(5):1869-79.

40. Chafekar S, Baas F, Scheper W. Oligomer-specific amyloid-beta toxicity in cell models is mediated by selective uptake. Biochem Biophys Acta. 2008;1782(9):523-31.

41. Hu X, Crick S, Guojun B, Carl F, Rohit VP, Jin ML. Amyloid seeds formed by cellular uptake, concentration, and aggregation of the amyloid-beta peptide. Proc Natl Acad Sci USA. 2009;106(48):20324-9.

42. Yajima R, Tokutake T, Koyama A, Kasuga K, Tezuka T, Nishizawa M, et al. ApoEisoform-dependent cellular uptake of amyloid- $\beta$ is mediated by lipoprotein receptor LR11/SorLA. Biochem Biophys Res Comm. 2015;456:482-8.

43. Omtri R, Davidson M, Arumugam B, Joseph FP, Karunya KK. Differences in the Cellular Uptake and Intracellular Itineraries of Amyloid Beta Proteins 40 and 42: Ramifications for the Alzheimer's Drug Discovery. Mol Pharmaceutics. 2012;9(7):1887-97.

44. Bu G, Cam J, Zerbinatti C. LRP in amyloid- $\beta$ production and metabolism. Ann NY Acad Sci. 2006;1086:35-53.

45. Nagele R, D'Andrea M, Anderson W, Wang H. Intracellular accumulation of $\beta$-amyloid1-42 in neurons is facilitated by the $\alpha 7$ nicotinic acetylcholine receptor in Alzheimer's disease. Neuroscience. 2002;110:199-211.

46. Wang HY, Lee DH, D'Andrea MR, Peterson PA, Shank RP, Reitz AB. betaAmyloid(1-42) binds to $\alpha 7$ nicotinic acetylcholine receptor with high affinity. Implications for Alzheimer's disease pathology. J Biol Chem. 2000;275(8):5626-32.

47. Oddo S, Kim NG, Kevin L, Levina T, Yiling C, Frank ML, et al. Chronic nicotine administration exacerbates tau pathology in a transgenic model of Alzheimer's disease. Proc Natl Acad Sci USA. 2005;102(8):3046-51.

48. Deane R, Du Yan S, Submamaryan RK, Larue B, Jovanovic S, Hogg E, et al. RAGE mediates amyloid- $\beta$ peptide transport across the blood-brain barrier and accumulation in brain. Nature Med. 2003;9(7):907-13.

49. Yan S, Chen X, Fu J, Chen M, Zhu H, Roher A, et al. RAGE and amyloid- $\beta$ peptide neurotoxicity in Alzheimer's disease. Nature. 1996;382(6593):685-91.

50. Sasaki N, Sadamu T, Hiroshi C, Zenji M, Hayashi Y, Saito Y, et al. Immunohistochemical distribution of the receptor for advanced glycation end products in neurons and astrocytes in Alzheimer's disease. Brain Res. 2001;888(2):256-62. 
51. Iribarren P, Zhou Y, Hu J, Le Y, Wang J. Role of formyl peptide receptor-like 1 (FPRL1/ FPR2) in mononuclear phagocyte responses in Alzheimer disease. Immunol Res. 2005;31:165-76.

52. Snyder EM, Nong Y, Almeida CG, Paul S, Moran T, Choi EY, et al. Regulation of NMDA receptor trafficking by amyloid- $\beta$. Nat Neurosci. 2005;8(8):1051-8.

53. Kinoshita A, Fukumoto H, Shah T, Whelan CM, Hyman BT, Irizarry MC. Demonstration by FRET of BACE interaction with the amyloid precursor protein at the cell surface and in early endosomes. J Cell Sci. 2003;116(16):3339-46.

54. Xu H, Greengard P, Gandy S. Regulated formation of Golgi secretory vesicles containing Alzheimer $\beta$-amyloid precursor protein. J Biol Chem. 1995;270(40):23243-5.

55. Mizuguchi M, Ikeda K, Kim S. Differential distribution of cellular forms of $\beta$-amyloid precursor protein in murine glial cell cultures. Brain Res. 1992;584(2):219-25.

56. Cook D, Forman MS, Sung JC, Leight S, Kolson DL, Iwatsubo T, et al. Alzheimer's $A \beta(1-42)$ is generated in the endoplasmic reticulum/intermediate compartment of NT2N cells. Nature Med. 1997;3(9):1021-3.

57. Lee S, Liyanage U, Bickel PE, Xia W, Lansbury PT Jr, Kosik KS. A detergentinsoluble membrane compartment contains $\mathrm{A} \beta$ in vivo. Nature Med. 1998;4(6):730-4.

58. Skovronsky D, Doms R, Lee V. Detection of a novel intraneuronal pool of insoluble amyloid $\beta$ protein that accumulates with time in culture. J Cell Biol. 1998;141(4):1031-9.

59. Wild-Bode C, Yamazaki T, Anja C, Uwe L, Yasuo I, Haass C, et al. Intracellular generation and accumulation of amyloid beta-peptide terminating at amino acid 42 . J Biol Chem. 1997;272:16085-8.

60. Hartmann T, Babara B, David A, Colin LM, Gareth WR, Ida N, et al. Distinct sites of intracellular production for Alzheimer's disease A $\beta 40 / 42$ amyloid peptides. Nature Med. 1997;3:1016-20.

61. Wesen E, Jeffries G, Dzebo M, Esbjorner M. Endocytic uptake of monomeric amyloid- $\beta$ peptides is clathrin- and dynamin-independent and results in selective accumulation of $A \beta(1-42)$ compared to $A \beta(1-40)$. Sci Rep. 2017;7(1):2021.

62. Sannerud R, Carry E, Roger H, Mark M, Joost S, Wim A, et al. Restricted Location of PSEN2/gamma-Secretase Determines Substrate Specificity and Generates an Intracellular Abeta Pool. Cell. 2016;166:193-208.

63. Almeida C, Takahashi R, Gouras G. $\beta$-amyloid accumulation impairs multivesicular body sorting by inhibiting the ubiquitin-proteasome system. J Neurosci. 2006;26(16):4277-88

64. Gregori L, Fuchs C, Figueiredo-Pereira M, Van Nostrand W, Goldgaber D. Amyloid $\beta$-protein inhibits ubiquitin-dependent protein degradation in vitro. J Biol Chem. 1995;270:19702-8.

65. Oh S. Amyloid peptide attenuates the proteasome activity in neuronal cells. Mech. Ageing Dev. 2005;126:1292-9.

66. Tseng B, Green K, Chan J, Blurton-Jones M, LaFerla F. A $\beta$ inhibits the proteasome and enhances amyloid and tau accumulation. Neurobiol Aging. 2008;29:1607-18.

67. Manczak M. Mitochondria are a direct site of $A \beta$ accumulation in Alzheimer's disease neurons: implications for free radical generation and oxidative damage in disease progression. Hum. Mol. Genet. 2006;15:1437-49.

68. Hansson C. Nicastrin, presenilin, APH-1, and PEN-2 form active $\beta$-secretase complexes in mitochondria. J Biol Chem. 2004;279:51654-60.

69. Caspersen C. Mitochondrial A $\beta$ : a potential focal point for neuronal metabolic dysfunction in Alzheimer's disease. FASEB J. 2005;19:2040-1.

70. Volloch V. A mechanism for $ß$-amyloid overproduction in Alzheimer's disease: Precursor-independent generation of $B$-amyloid via antisense RNA-primed mRNA synthesis. FEBS Lett. 1996;390:124-8.

71. Volloch V. Mechanism for B-amyloid overproduction in sporadic Alzheimer's Disease: Possible antisense RNA-mediated generation of a 5'-truncated BAPP mRNA encoding $12 \mathrm{kDa}$ C-terminal fragment of $\mathrm{BAPP}$, the immediate precursor of $\mathrm{A} B$. In: Molecular Mechanisms of Dementia. 1997, W. Wasco and R. Tanzi, Eds.

72. Volloch V. Possible mechanism for resistance to Alzheimer's disease (AD) in mice suggests new approach to generate a mouse model for sporadic AD and may explain familial resistance to AD in man. Exp Neurobiol. 1997;144:214-8.

73. Volloch, V, Rits S. Results of beta secretase-inhibitor clinical trials support amyloid precursor protein-independent generation of beta amyloid in sporadic Alzheimer's disease. Med Sci. 2018.

74. Volloch V, Olsen BR, Rits S. Precursor-Independent Overproduction of BetaAmyloid in AD: Mitochondrial Dysfunction as Possible Initiator of Asymmetric RNA-Dependent $\beta$ APP mRNA Amplification. An Engine that Drives Alzheimer's Disease. Ann Integr Mol Med. 2019;1(1):1005.

75. Volloch V, Olsen BR, Rits S. AD "Statin": Alzheimer's Disorder is a "Fast" Disease Preventable by Therapeutic Intervention Initiated Even Late in Life and Reversible at the Early Stages. Ann Integr Mol Med. 2020;2(1):1006.

76. Lai M. RNA replication without RNA-dependent RNA polymerase: surprises from hepatitis delta virus. J Virol. 2005;79:7951-8.

77. Taylor J. Replication of human hepatitis delta virus: recent developments. Trends Microbiol. 2003;11:185-90.

78. Tseng C, Lai M. Hepatatis delta virus RNA replication. Viruses. 2009;1:818-31

79. Lehmann E, Brueckner F, Cramer P. Molecular basis of RNA-dependent RNA polymerase II activity. Nature. 2007;450:445-9.

80. Wagner S, Yakovchuk P, Ponicsan S, Drullinger L, Kugel J, Goodrich J. RNA polymerase II acts as an RNA-dependent RNA polymerase to extend and destabilize non-coding RNA. EMBO J. 2013;32:781-90.

81. Maida Y, Yasukawa M, Masutomi K. De Novo RNA Synthesis by RNA-Dependent RNA Polymerase Activity of Telomerase Reverse Transcriptase. Mol Cell Biol. 2016;38:1248-59.

82. Downey K, Byrnes J, Jurmark B, So A. Reticulocyte RNA-Dependent RNA Polymerase. Proc Nat Acid Sci USA. 1973:70:3400-4

83. Kapranov P, Ozsolak F, Kim S, Foissac S, Lipson D, Hart C, et al. New class of genetermini-associated human RNAs suggests a novel RNA copying mechanism. Nature. 2010;466:642-6.

84. Volloch V, Schweitzer B, Rits S. Antisense Globin RNA in Murine Erythroid Tissues: Structure, Origin and Possible Function. Proc Natl Acad Sci USA. 1996;93:2476-81.

85. Volloch V. Protein-encoding RNA to RNA transfer in mammalian cells: Principles of RNA-dependent mRNA amplification. Ann Integr Mol Med. 2019;1(1):1002.

86. Rits S, Olsen BR, Volloch V. Protein-encoding RNA to RNA information transfer in mammalian cells: RNA-dependent mRNA amplification. Identification of chimeric RNA intermediates and putative RNA end products. Ann Integr Mol Med. 2019;1(1):1003.

87. Volloch V, Rits S, Olsen BR. RNA-dependent Amplification of Mammalian mRNA Encoding Extracellullar Matrix Proteins: Identification of Chimeric RNA Intermediates for $\alpha 1, \beta 1$, and $\gamma 1$ Chains of Laminin. Ann Integr Mol Med. 2019, 1(1): 1004

88. Richards O, Ehrenfeld E. Poliovirus RNA replication. Curr Topics Microbiol Immun 1990;161:89-119.

89. Brazas R, Ganem D. A cellular homolog of hepatitis delta antigen: implications for viral replication and evolution. Science. 1996;5284:90-4.

90. Huang C, Lo S. Evolution and diversity of human hepatitis D virus genome. Advance Bioinform. 2010.

91. Volloch V, Schwetizer B, Rits S. Evolutionarily Conserved Elements in the 5'-untranslated Region of beta-Globin mRNA Mediate Site-specific Priming of a Unique Hairpin Structure during cDNA Synthesis. Nucl Acids Res. 1994;22:5302-9.

92. Breimer L Denny P. Alzheimer amyloid aspects. Nature. 1987;326:749-50.

93. Citron M, Haass C, Selkoe D. Production of amyloid beta peptide by cultured cells: no evidence for internal initiation of translation at Met596. Neurobiol Aging. $1993 ; 14: 571-3$

94. Mita S, Sadlock J, Herbert J, Schon E. A cDNA specifying the human amyloid beta precursor protein encodes a 95-kDa polypeptide. Nucl Acids Res. 1988;16:9351. 
95. Mita S, Sadlock J, Herbert J, Schon E. A cDNA specifying the human amyloid beta precursor protein encodes a $95-\mathrm{kDa}$ polypeptide: Correction. Nucl. Acids Res. 1988;16:11402.

96. Salbaum J, Weidemann A, Lemaire H, Masters C, Beyreuther K. The promoter of Alzheimer's disease amyloid A4 precursor gene. EMBO J. 1988;7:2807-13.

97. Yoshida H, Matsui T, Yamamoto A, Okada T, Mori K. XBP1 mRNA is induced by ATF6 and spliced by IRE1 in response to ER stress to produce a highly active transcription factor. Cell. 2001;107(7):881-91.

98. Jiang S, Zhang E, Zhang R, Li X. Altered activity patterns of transcription factors induced by endoplasmic reticulum stress. BMC Biochem. 2016;17:8.

99. Rabouille C. Pathways of unconventional protein secretion. Trends Cell Biol. 2017;27(3):230-40.

100. Zhu X, Perry G, Moreira PI, Aliev G, Cash AD, Hirai K, et al. Mitochondrial abnormalities and oxidative imbalance in Alzheimer disease. J Alzheimers Dis. 2006;9:147-53.

101. Blass JP. The mitochondrial spiral. An adequate cause of dementia in the Alzheimer's syndrome. Ann N Y Acad Sci. 2000;924:170-83.

102. Manczak M, Park BS, Jung Y, Reddy PH. Differential expression of oxidative phosphorylation genes in patients with Alzheimer's disease: implications for early mitochondrial dysfunction and oxidative damage. Neuromolecular Med. 2004;5:147- 62 .

103. Qin W, Haroutunian V, Katsel P, Cardozo CP, Ho L, Buxbaum JD, et al. PGClalpha expression decreases in the Alzheimer disease brain as a function of dementia. Arch Neurol. 2009;66:352-61.

104. Du H, Guo L, Yan S, Sosunov AA, McKhann GM, Yan SS. Early deficits in synaptic mitochondria in an Alzheimer's disease mouse model. Proc Natl Acad Sci U S A. 2010;107:18670-5.

105. Lin MT, Simon DK, Ahn CH, Kim LM, Beal MF. High aggregate burden of somatic mtDNA point mutations in aging and Alzheimer's disease brain. Hum Mol Genet. 2002;11:133-45.

106. Calkins M, Manczak M, Mao P, Shirendeb U, Reddy PH. Impaired mitochondrial biogenesis, defective axonal transport of mitochondria abnormal mitochondrial dynamics and synaptic degeneration in a mouse model of Alzheimer's disease. Hum Mol Genet. 2011

107. Anandatheerthavarada HK, Biswas G, Robin MA, Avadhani NG Mitochondrial targeting and a novel transmembrane arrest of Alzheimer's amyloid precursor protein impairs mitochondrial function in neuronal cells. J Cell Biol. 2003;161:41-54.

108. Caspersen C, Wang N, Yao J. Mitochondrial A-beta: a potential focal point for neuronal metabolic dysfunction in Alzheimer's disease. FASEB J. 2005;19:2040-1.

109. Chen JX, Yan SS. Role of mitochondrial amyloid-beta in Alzheimer's disease. J Alzheimers Dis. 2010;20(2):S569-78.

110. Hansson Petersen CA, Alikhani N, Behbahani H. The amyloid beta-peptide is imported into mitochondria via the TOM import machinery and localized to mitochondrial cristae. Proc Natl Acad Sci U S A. 2008;105:13145-50.

111. de la Monte SM, Luong T, Neely TR, Robinson D, Wands JR. Mitochondrial DNA damage as a mechanism of cell loss in Alzheimer's disease. Lab Invest. 2000;80:1323-35

112. Brooks WM, Lynch PJ, Ingle CC, Hatton A, Emson PC, Faull RL, et al. Gene expression profiles of metabolic enzyme transcripts in Alzheimer's disease. Brain Res. 2007;1127:127-35.

113. Wang X, Perry G, Smith MA, Zhu X. Amyloid-beta-derived diffusible ligands cause impaired axonal transport of mitochondria in neurons. Neurodegener Dis. 2015;7:56-9.

114. Wang X, Su B, Fujioka H, Zhu X. Dynamin-like protein 1 reduction underlies mitochondrial morphology and distribution abnormalities in fibroblasts from sporadic Alzheimer's disease patients. Am J Pathol. 2008a;173:470-82.
115. Wang X, Su B, Lee HG, Li X, Perry G, Smith MA, et al. Impaired balance of mitochondrial fission and fusion in Alzheimer's disease. $J$ Neurosci. 2009;29:9090-103.

116. Wang X, Su B, Siedlak SL, Moreira PI, Fujioka H, Wang Y, et al. Amyloid-beta overproduction causes abnormal mitochondrial dynamics via differential modulation of mitochondrial fission/fusion proteins. Proc Natl Acad Sci U S A. 2008b;105:19318-23.

117. Su B, Wang X, Bonda D, Perry G, Smith M, Zhu X. Abnormal mitochondrial dynamics--a novel therapeutic target for Alzheimer's disease? Mol Neurobiol. 41:87-96.

118. Manczak M, Calkins MJ, Reddy PH. Impaired mitochondrial dynamics and abnormal interaction of amyloid beta with mitochondrial protein Drp1 in neurons from patients with Alzheimer's disease: implications for neuronal damage. Hum Mol Genet. 2011;20(13):2495-509.

119. Leuner K, Schütt T, Kurz C, Eckert SH, Schiller C, Occhipinti A, et al. Mitochondrion-derived reactive oxygen species lead to enhanced amyloid beta formation. Antioxid Redox Signal. 2012;16(12):1421-33.

120. LaFerla FM, Green KN, Oddo S. Intracellular amyloid- $\beta$ in Alzheimer's disease. Nat Rev Neurosci. 2007;8(7):499-509.

121. Lapointe J, Hekimi S. Early mitochondrial dysfunction in long-lived Mclk1+/- mice. J Biol Chem. 2008;283(38):26217-27.

122. Chu Q, Martinez T, Novak S, Donaldson C, Tan D, Chang T, et al. Regulation of the ER stress response by a mitochondrial microprotein. Nat Commun. 2019;10(1):4883.

123. Teo E, Ravi S, Barardo D, Kim H, Fong S, Tan TY, et al. Metabolic stress is a primary pathogenic event in transgenic Caenorhabditis elegans expressing panneuronal human amyloid beta. ELife. 2019.

124. Suzuki N, Cheung T, Cai X, Odaka A, Otvos L Jr, Eckman C, et al. An increased percentage of long amyloid beta protein secreted by familial amyloid beta protein precursor (beta APP717) mutants. Science. 1994;264(5163):1336-40.

125. Maruyama K, Tomita T, Shinozaki K, Kume H, Hideo A, Obata K, et al. Familial Alzheimer's disease-linked mutations at Val717 of amyloid precursor protein are specific for the increased secretion of A beta 42(43). Biochem Biophys Res Commun. 1996;227(3):730-5.

126. Dimitrov M, Alattia JR, Thomas L, Lehal R, Fligier A, Dirk B, et al. Alzheimer's disease mutations in APP but not gamma-secretase modulators affect epsilon-cleavage-dependent AICD production. Nat Commun. 2013.

127. Weggen S, Beher D. Molecular consequences of amyloid precursor protein and presenilin mutations causing autosomal-dominant Alzheimer's disease. Alzheimers Res Ther. 2012;4(2):9.

128. Reinert J, Bernhard CR, Hans KW, Thomas AB, Jens W, Martin I, et al. Deposition of C-terminally truncated $A \beta$ species $A \beta 37$ and $A \beta 39$ in Alzheimer's disease and transgenic mouse models. Acta Neuropathol Commun. 2016;4:24.

129. Dunys J, Valverde A, Checler F. Are N- and C-terminally truncated A $\beta$ species key pathological triggers in Alzheimer's disease? J Biol Chem. 2018;293(40):15419-28.

130. Cabrera E, Mathews P, Mezhericher E, Beach TG, Deng J, Neubert TA, et al. A $\beta$ truncated species: Implications for brain clearance mechanisms and amyloid plaque deposition. Biochem Biophys Acta. 2018;1864(1):208-25.

131. Elder G, Sosa M, DeGasperi R. Transgenic mouse models of Alzheimer's disease. Mt Sinai J Med. 2010;77(1):69-81.

132. Wertkin A, Turner RS, Pleasure SJ, Golde TE, Younkin SG, Lee VM, et al. Human neurons derived from a teratocarcinoma cell line express solely the 695-amino acid amyloid precursor protein and produce intracellular betaamyloid or A4 peptides. Proc Natl Acad Sci USA. 1993;90(20):9513-7.

133. Macias M, Gonzales AM, Siniard AL, Walker AW, Corneveaux JJ, Huentelman MJ, et al. A Cellular Model of Amyloid Precursor Protein Processing and Amyloid- $\beta$ Peptide Production. J Neurosci Methods. 2014;223:114-22. 
134. Andres D, Keyser BM, Petrali J, Benton B, Hubbard KS, McNutt PM. et al Morphological and functional differentiation in BE(2)-M17 human neuroblastoma cells by treatment with Trans-retinoic acid. BMC Neurosci. 2013;14:49.

135. Song Y, Subramanian K, Berberich M, Rodriguez S, Latorre IJ, Luria CM, et al. A dynamic view of the proteomic landscape during differentiation of ReNcell VM cells, an immortalized human neural progenitor line. Sci Data. 2019;6:190016.
136. Meyer K, Heather MF, Tao L, Derek D, Lim EL, King HL, et al. REST and neural gene network dysregulation in iPSC models of Alzheimer's disease. Case Rep. 2019;26(5):1112-27.

137. Choi SH, Kim YH, Hebisch M, Sliwinski C, Lee S, D'Avanzo C, et al. A threedimensional human neural cell culture model of Alzheimer's disease. Nature. 2014;515(7526):274-8. 